\title{
Ultrathin Silicon Oxide Overlayers Enable Selective Oxygen Evolution from Acidic and Unbuffered pH-Neutral Seawater
}

Amar A. Bhardwaj, Johannes G. Vos, Marissa E. S. Beatty, Amanda F. Baxter, Marc T. M. Koper, Ngai Yin Yip, and Daniel V. Esposito*

Cite This: ACS Catal. 2021, 11, 1316-1330

Read Online

ACCESS | Llll Metrics \& More | 回 Article Recommendations | sl Supporting Information

ABSTRACT: Seawater electrolysis is an attractive approach for producing clean hydrogen fuel in Selectively Permeable scenarios where freshwater is scarce and renewable electricity is abundant. However, chloride ions $\left(\mathrm{Cl}^{-}\right)$in seawater can accelerate electrode corrosion and participate in the undesirable chlorine evolution reaction (CER). This problem is especially acute in acidic conditions that naturally arise at the anode as a result of the desired oxygen evolution reaction (OER). Herein, we demonstrate that ultrathin silicon oxide $\left(\mathrm{SiO}_{x}\right)$ overlayers on model platinum anodes are highly effective at suppressing the CER in the presence of $0.6 \mathrm{M} \mathrm{Cl}^{-}$in both acidic and unbuffered $\mathrm{pH}$-neutral electrolytes by blocking the transport of $\mathrm{Cl}^{-}$to the catalytically active buried interface while allowing the desired oxygen evolution reaction (OER) to occur there. The permeability of $\mathrm{Cl}^{-}$in $\mathrm{SiO}_{x}$ overlayers is 3 orders of magnitude less than that of $\mathrm{Cl}^{-}$in a conventional salt-selective membrane used in reverse osmosis desalination. The overlayers also exhibit robust stability over 12

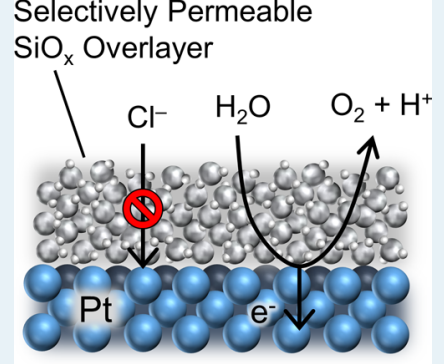
$\mathrm{h}$ in chronoamperometry tests at moderate overpotentials. $\mathrm{SiO}_{x}$ overlayers demonstrate a promising step toward achieving selective and stable seawater electrolysis without the need to adjust the $\mathrm{pH}$ of the electrolyte.

KEYWORDS: seawater electrolysis, oxygen evolution reaction, chlorine evolution reaction, membrane-coated electrocatalysts, hydrogen, silicon oxide, coatings

\section{INTRODUCTION}

“Green” hydrogen produced from water electrolysis powered by renewable electricity is a valuable zero emission energy carrier that could serve as an energy storage medium for intermittent renewable energy, a clean fuel in the transportation sector, or a feedstock for the chemical industry. ${ }^{1-4}$ Producing green hydrogen by directly splitting abundant seawater instead of freshwater avoids competition for freshwater in locations and applications where freshwater is scarce 5 and avoids the need for costly desalination of seawater. However, a major challenge to seawater electrolysis is that chloride ions, the predominant anion in seawater, participate in unfavorable side reactions at the anode that are in competition with the desired oxygen evolution reaction (OER, eq 1 ). In acidic conditions, chloride ions can combine to form chlorine $\left(\mathrm{Cl}_{2}\right)$ through the chlorine evolution reaction (CER, eq 2), while hypochlorite $\left(\mathrm{OCl}^{-}\right)$is believed to be produced according to eq 3 in alkaline conditions ${ }^{7}$

$$
\begin{aligned}
& 2 \mathrm{H}_{2} \mathrm{O} \rightarrow \mathrm{O}_{2}+4 \mathrm{H}^{+}+4 \mathrm{e}^{-} ; E^{0}=1.23 \mathrm{~V} \text { vs RHE } \\
& 2 \mathrm{Cl}^{-} \rightarrow \mathrm{Cl}_{2}+2 \mathrm{e}^{-} ; E^{0}=(1.36+0.059 \cdot \mathrm{pH}) \mathrm{V} \text { vs RHE }
\end{aligned}
$$

$\mathrm{Cl}^{-}+2 \mathrm{OH}^{-} \rightarrow \mathrm{ClO}^{-}+\mathrm{H}_{2} \mathrm{O}+2 \mathrm{e}^{-}$;

$E^{0}=1.71 \mathrm{~V}$ vs RHE
Although $\mathrm{Cl}_{2}$ and $\mathrm{OCl}^{-}$have commercial value, global demand for hydrogen is projected to reach over 40 times the demand for chlorine on a mole basis by $2024 .^{8-10}$ Producing $\mathrm{H}_{2}$ at scale from seawater electrolysis while generating equimolar quantities of $\mathrm{Cl}_{2}$ at the anode would soon lead to $\mathrm{Cl}_{2}$ generation in excess of demand for chlorine. The excess toxic chlorine produced would be exceedingly difficult to manage and dispose of. On the other hand, the production of $\mathrm{O}_{2}$ at the anode during seawater electrolysis would not be subject to the same management difficulties as $\mathrm{Cl}_{2}$.

To achieve truly sustainable, large-scale hydrogen production from direct seawater electrolysis, it is therefore critically important to develop electrocatalysts and electrolyzer systems that selectively evolve $\mathrm{O}_{2}$ at the anode. Unfortunately, the kinetics of $\mathrm{Cl}^{-}$oxidation tend to be more favorable than those for the OER, in part because $\mathrm{Cl}^{-}$oxidation requires the transfer of two electrons, while the OER is a four-electron reaction. ${ }^{11}$ The most common approach to enhance $\mathrm{O}_{2} / \mathrm{Cl}_{2}$ selectivity is to increase the $\mathrm{pH}$ of seawater to carry out alkaline seawater electrolysis, $3,5,7,12,13$ which makes the stand-

Received: October 6, 2020

Revised: December 24, 2020

Published: January 12, 2021

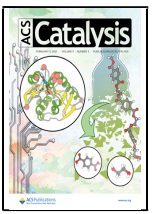


ard reduction potential for the OER $\approx 0.48 \mathrm{~V}$ more negative than that for $\mathrm{OCl}^{-}$formation. ${ }^{7}$ Thanks to this thermodynamic advantage and the abundance of stable and relatively active OER electrocatalysts in alkaline conditions, there have been many reports of OER faradic efficiencies (FEs) close to $100 \%$ during alkaline seawater electrolysis. ${ }^{5,7,12-21}$ However, a major disadvantage of alkaline seawater electrolysis is that lye and fresh seawater must be continuously flushed through the electrolyzer to sustain an elevated $\mathrm{pH}$ and avoid producing concentrated brine, respectively. ${ }^{22,23}$ The consumption of lye, as well as acid to neutralize the effluent stream, adds unwanted complexity, energy use, and cost to the system. ${ }^{24}$ Furthermore, alkaline seawater electrolysis still faces the challenge of local acidification at the anode caused by the OER at very high current densities, which will eventually lead to the CER and/or stability issues. $^{25-27}$

As an alternative to alkaline seawater electrolysis, the direct electrolysis of seawater at near-neutral $\mathrm{pH}$ could avoid the drawbacks associated with adding lye to the electrolyzer system. A pH-neutral environment is also more favorable for hybrid biological/electrochemical systems containing bacteria that cannot survive at the $\mathrm{pH}$ extremes typically encountered in water electrolysis. ${ }^{28,29}$ A central challenge of realizing $\mathrm{pH}$ neutral seawater electrolysis is that the oxidation of $\mathrm{H}_{2} \mathrm{O}$ according to eq 1 coproduces $\mathrm{H}^{+}$ions, creating locally acidic conditions at the anode. This shifts the reversible potential for the OER closer to that for the CER while placing significant constraints on material options due to the lack of acid-stable OER catalysts that can operate at elevated current densities for significant periods of time. ${ }^{30-34}$ To address these challenges, researchers often add $\mathrm{pH}$ buffers to maintain the electrolyte at a $\mathrm{pH}$ of 7 or above. ${ }^{35-38}$ However, this entails continually adding buffer species to the electrolysis solution, and buffers may not be able to prevent large $\mathrm{pH}$ changes from occurring at the electrode-electrolyte interface at high OER current densities. $^{27,39}$ Further, unprotected electrocatalysts exposed to seawater of any $\mathrm{pH}$ are susceptible to corrosion from chlorine-based ions and molecules. ${ }^{40}$ This challenge motivates exploration of solutions that go beyond engineering the $\mathrm{pH}$ of the electrolyte.

Recent studies have shown that rational control of species transport, rather than chemical kinetics, offers a promising approach to tune electrocatalyst selectivity for the desired reaction. ${ }^{41,42}$ Overlayers composed of various semipermeable materials have been coated onto OER electrocatalysts to selectively reject the transport of chloride ions to the buried interface between the catalyst and overlayer while allowing diffusion of $\mathrm{H}_{2} \mathrm{O}$ to the buried interface, ${ }^{12,13,32-34,43-45}$ a necessity for the OER. The semipermeable overlayer in these encapsulated electrocatalysts thus provides selectivity for the OER over the CER and also offers the potential to block chloride-induced corrosion of the underlying OER electrocatalyst or chloride-induced leaching of OER catalyst material. $^{46-48}$

However, previously reported overlayers have not demonstrated high OER selectivity and robust stability in the highly acidic environment created at the catalyst surface during the OER. In one notable study, semipermeable manganese oxide $\left(\mathrm{MnO}_{x}\right)$ overlayers deposited onto $\mathrm{IrO}_{x}$ anode catalysts were shown to enable high transport-based selectivity for the OER over the CER in weakly acidic conditions. ${ }^{43}$ Although $\mathrm{MnO}_{x}$ is not thermodynamically stable in acidic conditions at potentials typically used for the OER, $\mathrm{MnO}_{x}$-based OER electrocatalysts can be functionally stable due to a "self-healing" mechanism, whereby $\mathrm{MnO}_{x}$ is continuously regenerated on the anode through oxidation of dissolved $\mathrm{Mn}$ ions. ${ }^{43,49}$ However, $\mathrm{MnO}_{x}$ is not functionally stable at the extremely low local $\mathrm{pH}$ conditions that may arise at the electrode during the OER at high current densities. ${ }^{49,50}$ Additionally, the need to flow electrolyte through the electrolyzer is likely to lead to longterm degradation of ultrathin $\mathrm{MnO}_{x}$ coatings as dissolved $\mathrm{Mn}$ ions are gradually swept away from the electrode.

In this study, ultrathin semipermeable overlayers of silicon oxide $\left(\mathrm{SiO}_{x}\right)$ were investigated as alternative electrocatalyst coatings for selectively rejecting chloride ion transport in acidic and unbuffered pH-neutral solutions (Figure 1). Nanoscale

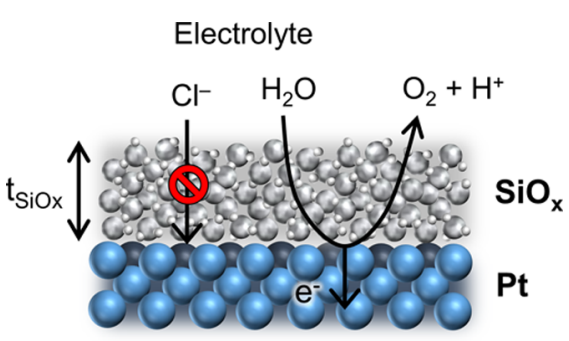

Figure 1. Schematic showing the planar $\mathrm{SiO}_{x}$-encapsulated Pt thin film electrode capable of selectively blocking the undesired chlorine evolution reaction while permitting the desired oxygen evolution reaction to occur at the catalytic buried interface.

$\mathrm{SiO}_{x}$ films have previously been shown to function as highly selective "nanomembranes", including for $\mathrm{SiO}_{x}$-modified gasdiffusion membranes, ${ }^{51}$ and in electrocatalytic applications where they have been coated onto electrodes. ${ }^{52-54}$ Further, silicon oxide is thermodynamically stable across a wide range of potentials in acidic and $\mathrm{pH}$-neutral conditions ${ }^{55}$ and is generally considered to be a catalytically inert material that will not promote reactions on its outer interface where it contacts the chloride-containing bulk electrolyte.

$\mathrm{SiO}_{x}$ overlayers investigated in this work were deposited onto well-defined $\mathrm{Pt}$ thin film electrocatalysts using a roomtemperature photochemical process in which a poly(dimethylsiloxane) (PDMS) precursor was spin-coated onto the electrocatalyst surface and then converted to $\mathrm{SiO}_{x}$ by exposure to UV-generated ozone. By varying the initial PDMS concentration, this method affords nanometer-level control of overlayer thickness and produces continuous $\mathrm{SiO}_{x}$ films of uniform thickness that are characterized by surface root mean square (rms) roughness values less than $1 \mathrm{~nm} .{ }^{52}$ The density of the overlayers has been estimated to be $2.56 \mathrm{~g} \mathrm{~cm}^{-3}$, corresponding to a free volume fraction of $3.3 \%$ if the filled volume elements of the $\mathrm{SiO}_{x}$ are assumed to have an identical density to void-free $\alpha$-quartz. ${ }^{56} \mathrm{SiO}_{x}$ overlayers do not possess well-defined pores spanning the thickness of the film, but instead contain less ordered, sub-nanometer-sized free volume elements. ${ }^{53} \mathrm{Pt}$ was chosen as the active catalyst material because of its high activity for the CER and relatively poor activity for the OER, making it an ideal platform for easily deconvoluting OER and CER currents in voltammograms thanks to the significant differences in the OER and CER onset potentials.

Using these model $\mathrm{SiO}_{x}$-encapsulated $\mathrm{Pt}$ electrodes $\left(\mathrm{SiO}_{x} \mathrm{I}\right.$ $\mathrm{Pt}$ ), we show that nanoscopic $\mathrm{SiO}_{x}$ overlayers are highly effective at blocking $\mathrm{Cl}^{-}$from reaching the electrocatalytic buried interface, markedly suppressing the CER at over- 
(a)

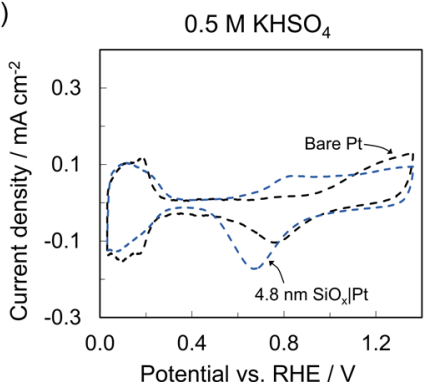

(b)

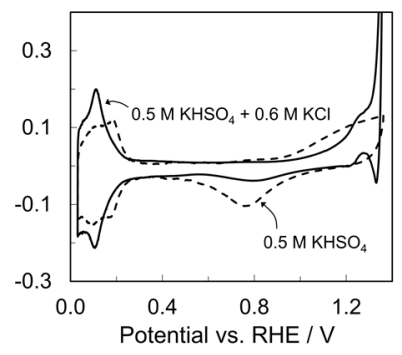

(c)

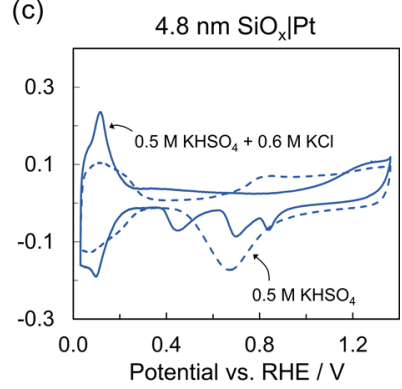

Figure 2. CV measurements for (a) bare Pt (black curves) and $4.8 \mathrm{~nm} \mathrm{SiO} \mathrm{SPt}_{x}$ (blue curves) in $0.5 \mathrm{M} \mathrm{KHSO}_{4}$. $\mathrm{CV}$ measurements for (b) bare Pt and (c) $4.8 \mathrm{~nm} \mathrm{SiO}_{x} \mid \mathrm{Pt}$ in $0.5 \mathrm{M} \mathrm{KHSO}_{4}$ (dashed curves) and $0.5 \mathrm{M} \mathrm{KHSO}_{4}+0.6 \mathrm{M} \mathrm{KCl}$ (solid curves). All measurements were performed at 100 $\mathrm{mV} \mathrm{s}^{-1}$ in deaerated electrolyte at $\mathrm{pH} 0.8$ and $25^{\circ} \mathrm{C}$.

potentials exceeding $500 \mathrm{mV}$ while still permitting for the desirable OER to occur. The overlayers greatly improve catalyst selectivity for the OER in unbuffered $\mathrm{pH}$-neutral and acidic seawater conditions and show potential to protect the catalyst from chlorine corrosion. We further demonstrate the robust stability of the $\mathrm{SiO}_{x}$ overlayers under prolonged operation in acidic conditions and at large overpotentials. The possible mechanisms of selective transport through the overlayers are also discussed.

\section{RESULTS AND DISCUSSION}

2.1. Cyclic Voltammetry (CV) of $\mathrm{SiO}_{x} \mathrm{IPt}$ Electrodes. The electrochemical characteristics of the as-made $\mathrm{SiO}_{x} \mathrm{IPt}$ electrodes were first evaluated by conducting cyclic voltammetry $(\mathrm{CV})$ in a $0.5 \mathrm{M} \mathrm{KHSO}_{4}(\mathrm{pH}=0.8)$ supporting electrolyte (Figure 2a). The oxidation and reduction peaks located between 0.0 and $0.3 \mathrm{~V}$ vs reversible hydrogen electrode (RHE) arise from hydrogen underpotential deposition $\left(\mathrm{H}_{\text {upd }}\right)$ and can be integrated to determine the electrochemically active surface area (ECSA) of the electrodes. Consistent with our previous studies of $\mathrm{SiO}_{x}$-encapsulated $\mathrm{Pt}$ thin films, ${ }^{52-54}$ the integrated $\mathrm{H}_{\text {upd }}$ signal for the $4.8 \mathrm{~nm} \mathrm{SiO} \mathrm{S}_{x} \mathrm{Pt}$ electrode is only $4 \%$ less than that of bare $\mathrm{Pt}$, suggesting that the Pt surface at the buried interface between $\mathrm{Pt}$ and $\mathrm{SiO}_{x}$ is still catalytically active and accessible to protons for $\mathrm{H}_{\text {upd }}$ by diffusion through the overlayer. Although the total integrated $\mathrm{H}_{\text {upd }}$ signals for the two samples are similar, the $\mathrm{H}_{\text {upd }}$ features for the $4.8 \mathrm{~nm} \mathrm{SiO}{ }_{x} \mathrm{l}$ Pt electrode exhibit slight differences in shape and extend roughly $40 \mathrm{mV}$ more positive than those for the bare $\mathrm{Pt}$.

As the applied potential is swept from the $\mathrm{H}_{\text {upd }}$ region to more positive potentials, oxidation current is observed that is associated with $\mathrm{Pt}$ oxidation to platinum hydroxides and oxides $\left(\mathrm{PtO}_{x}\right)$. After reversing scan directions at the positive vertex, this $\mathrm{PtO}_{x}$ is subsequently reduced back to metallic Pt. Similar to previous reports, ${ }^{52,54,57}$ the onset potential for $\mathrm{PtO}_{x}$ formation is shifted negative by $\approx 180 \mathrm{mV}$ for the $\mathrm{SiO}_{x}$ encapsulated sample compared to that for bare $\mathrm{Pt}$. We attribute this shift in the $\mathrm{PtO}_{x}$ onset potential, as well as the aforementioned shift in the $\mathrm{H}_{\text {upd }}$ peaks, to the ability of the $\mathrm{SiO}_{x}$ overlayers to block bisulfate ions $\left(\mathrm{HSO}_{4}{ }^{-}\right)$from interacting with the buried interface. $\mathrm{HSO}_{4}{ }^{-}$ions are known to adsorb competitively onto $\mathrm{Pt}$ at potentials negative of the $\mathrm{OH} / \mathrm{O}$ species adsorption that marks the first step of $\mathrm{Pt}$ oxidation, thereby inhibiting this step and shifting the $\mathrm{PtO}_{x}$ formation onset potential to more positive potentials. ${ }^{58-60}$ This positive shift is clearly observed for bare Pt but is absent from the $4.8 \mathrm{~nm} \mathrm{SiO}_{x} \mid \mathrm{Pt}$ electrode, for which the Pt oxidation onset potential of $0.6 \mathrm{~V}$ vs RHE is consistent with that typically observed in aqueous acidic electrolytes lacking adsorbing counterions. ${ }^{59}$ Similarly, the ability of $\mathrm{SiO}_{x}$ to block $\mathrm{HSO}_{4}{ }^{-}$ may explain why the $\mathrm{H}_{\text {upd }}$ region of the $\mathrm{SiO}_{x} \mid \mathrm{Pt}$ electrode extends to slightly more positive potentials than that for bare $\mathrm{Pt}$, as $\mathrm{HSO}_{4}^{-}$adsorption can compete with $\mathrm{H}^{+}$adsorption.

$\mathrm{CV}$ of bare $\mathrm{Pt}$ and $4.8 \mathrm{~nm} \mathrm{SiO}_{x} \mid \mathrm{Pt}$ electrodes were also carried out using identical scan conditions in a $0.6 \mathrm{M} \mathrm{KCl}$ solution containing the same $0.5 \mathrm{M} \mathrm{KHSO}_{4}$ supporting electrolyte, where the $\mathrm{KCl}$ concentration was set to mimic the average chloride concentration found in natural seawater. ${ }^{61}$ Though this $0.5 \mathrm{M} \mathrm{KHSO}_{4}+0.6 \mathrm{M} \mathrm{KCl}$ saline electrolyte has a higher ionic strength than the $0.5 \mathrm{M} \mathrm{KHSO}_{4}$ supporting electrolyte, additional $\mathrm{CV}$ and linear sweep voltammetry (LSV) measurements for bare $\mathrm{Pt}$ in modified supporting electrolytes with the same ionic strength as the saline electrolyte show a minimal influence of ionic strength on the measurements (Figure S1). In Figure 2b,c, CV curves in $0.5 \mathrm{M}$ $\mathrm{KHSO}_{4}+0.6 \mathrm{M} \mathrm{KCl}$ were superimposed on the CV curves in $0.5 \mathrm{M} \mathrm{KHSO}_{4}$ for bare $\mathrm{Pt}$ and $4.8 \mathrm{~nm} \mathrm{SiO}_{x} \mid \mathrm{Pt}$ electrodes, respectively. Both samples exhibit substantial differences in $\mathrm{CV}$ characteristics in the $0.5 \mathrm{M} \mathrm{KHSO}_{4}+0.6 \mathrm{M} \mathrm{KCl}$ saline electrolyte. Most noticeable for the bare Pt electrode $\mathrm{CV}$ in Figure $2 \mathrm{~b}$ is the appearance of a large oxidation peak associated with the CER close to the positive scan vertex. Concurrently, $\mathrm{H}_{\text {upd }}$ peaks on bare $\mathrm{Pt}$ are pushed to even more negative potentials, and the $\mathrm{PtO}_{x}$ peaks in both the positive and negative scan directions are significantly suppressed. Both of these changes can be attributed to $\mathrm{Cl}^{-}$adsorption, with the latter being consistent with previous publications reporting that $\mathrm{Cl}^{-}$adsorption suppresses Pt oxidation. ${ }^{58,59,62}$

As shown in the CV cycles in Figure $2 \mathrm{c}$, the $4.8 \mathrm{~nm} \mathrm{SiO} \mathrm{IPt}^{\mathrm{Pt}}$ electrode responds very differently to the presence of chloride ions compared to bare Pt. Most significant is the observation that virtually no CER oxidation peak is seen at positive potentials up to $1.35 \mathrm{~V}$, suggesting that the $\mathrm{SiO}_{x}$ overlayer might be blocking $\mathrm{Cl}^{-}$from reaching the catalytic buried interface. However, comparison of the $\mathrm{H}_{\text {upd }}$ and $\mathrm{PtO}_{x}$ features to those recorded in the supporting electrolyte indicates that the $\mathrm{SiO}_{x}$ is not completely impermeable to $\mathrm{Cl}^{-}$. As seen for the bare Pt electrode, the $\mathrm{H}_{\text {upd }}$ and Pt oxidation features for the 4.8 $\mathrm{nm} \mathrm{SiO} \mathrm{S}_{x} \mid \mathrm{Pt}$ electrode are also pushed to more negative and positive potentials, respectively, in the chloride-containing electrolyte.

Interestingly, the single $\mathrm{PtO}_{x}$ reduction peak on $\mathrm{SiO}_{x} \mid \mathrm{Pt}$ that was centered at $0.68 \mathrm{~V}$ vs RHE in the supporting electrolyte is replaced in the saline electrolyte with three different $\mathrm{PtO}_{x}$ reduction peaks centered at $0.45,0.70$, and $0.84 \mathrm{~V}$ vs RHE. The evolution of these curves throughout the course of $19 \mathrm{CV}$ 
a)

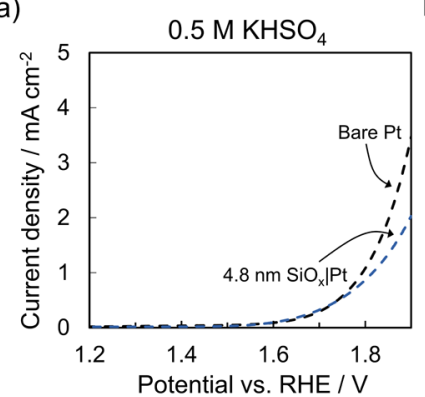

b)

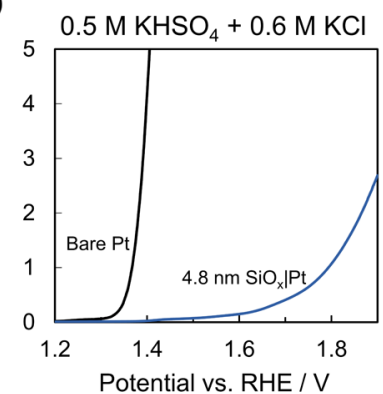

C)

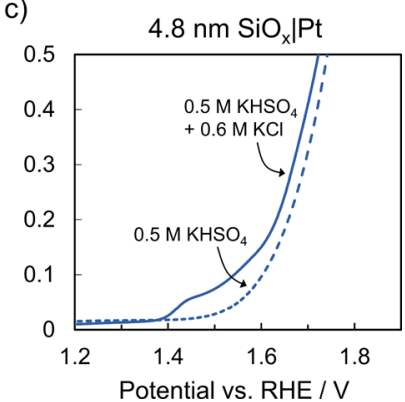

Figure 3. LSV measurements for bare $\mathrm{Pt}$ and $\mathrm{SiO}_{x} \mid \mathrm{Pt}$ electrodes in (a) $0.5 \mathrm{M} \mathrm{KHSO}_{4}$ and (b) $0.5 \mathrm{M} \mathrm{KHSO}_{4}+0.6 \mathrm{M} \mathrm{KCl}$. (c) $\mathrm{LSVs}$ for $4.8 \mathrm{~nm}$ $\mathrm{SiO}_{x} \mathrm{It}$ in $0.5 \mathrm{M} \mathrm{KHSO}_{4}$ and $0.5 \mathrm{M} \mathrm{KHSO}_{4}+0.6 \mathrm{M} \mathrm{KCl}$ (order-of-magnitude shorter vertical axis). All measurements were performed at $20 \mathrm{mV}$ $\mathrm{s}^{-1}$ in deaerated electrolyte at $\mathrm{pH} 0.8$ and $25{ }^{\circ} \mathrm{C}$.

cycles on $4.8 \mathrm{~nm} \mathrm{SiO} x \mid \mathrm{Pt}$ is provided in Figure S2. The first three $\mathrm{CV}$ cycles initiated immediately after immersion in the saline electrolyte show a $\mathrm{PtO}_{x}$ reduction peak consistent with the $\mathrm{CV}$ in the supporting electrolyte, indicating that $\mathrm{Cl}^{-}$has not yet reached the buried $\mathrm{Pt}$ surface. The three distinct $\mathrm{PtO}_{x}$ reduction peaks appear in subsequent cycles in the order of the $0.70 \mathrm{~V}$ peak, followed by the $0.45 \mathrm{~V}$ peak, and finally the 0.84 $\mathrm{V}$ peak. The gradual appearance of the three $\mathrm{PtO}_{x}$ reduction peaks suggests that chloride ions slowly diffuse through the $\mathrm{SiO}_{x}$ overlayer upon the electrode's initial immersion, eventually reaching low concentrations at the buried interface after several cycles. We postulate that these chloride ions encounter, and are possibly blocked from, different nanoconfined environments at the $\mathrm{SiO}_{x} \mid \mathrm{Pt}$ interface, potentially associated with different Pt crystal facets or grain boundaries, which give rise to multiple distinct $\mathrm{PtO}_{x}$ reduction peaks.

The total integrated charge for $\mathrm{PtO}_{x}$ reduction decreases for the $\mathrm{SiO}_{x} \mid \mathrm{Pt}$ electrode in the presence of $\mathrm{Cl}^{-}$but to a lesser extent $(\approx 55 \%$ decrease $)$ than was observed for bare Pt in Figure $2 \mathrm{~b}(\approx 75 \%$ decrease $)$. These changes in $\mathrm{PtO}_{x}$ reduction charge in the presence of $\mathrm{Cl}^{-}$can provide insight into the chloride concentration at the $\mathrm{SiO}_{x} \mid \mathrm{Pt}$ buried interface. Novak and Conway $^{62}$ demonstrated a logarithmic relationship between the percentage of $\mathrm{Pt}$ oxide "blocked" during $\mathrm{CV}$ cycling due to competitive adsorption of $\mathrm{Cl}^{-}$on a bare $\mathrm{Pt}$ electrode and the $\mathrm{KCl}$ concentration in the sulfuric acid electrolyte being used. According to this correlation, the 55\% decrease in $\mathrm{PtO}_{x}$ reduction signal we observe for $\mathrm{SiO}_{x} \mathrm{Pt}$ corresponds to $\mathrm{a} \approx 3 \mathrm{mM}$ concentration of $\mathrm{Cl}^{-}$, while the $75 \%$ decrease for bare $\mathrm{Pt}$ corresponds to $\approx 0.1 \mathrm{M} \mathrm{Cl}^{-}$. This analysis suggests that while a small concentration of $\mathrm{Cl}^{-}$reaches the buried $\mathrm{Pt}$ surface of $\mathrm{SiO}_{x} \mid \mathrm{Pt}$ in the presence of a $0.6 \mathrm{M}$ bulk chloride concentration, the selective $\mathrm{SiO}_{x}$ overlayer decreases the concentration of $\mathrm{Cl}^{-}$at the buried interface by roughly 2 orders of magnitude compared to that of bare $\mathrm{Pt}$ under identical CV cycling conditions.

The greatly lowered chloride concentration at the buried interface of $\mathrm{SiO}_{x} \mathrm{It}$ mitigates, but does not eliminate, the risk of chloride-induced corrosion of the underlying electrocatalyst. Pt-, Ir-, Fe-, Ni-, and Co-based OER electrocatalysts are all known to be susceptible to dissolution in the presence of $\mathrm{Cl}^{-}{ }^{48,63-66}$ Our analysis suggests that the $\mathrm{SiO}_{x}$ overlayer can decrease the chloride concentration at the buried electrocatalyst to millimolar levels in electrolytes containing $0.6 \mathrm{M}$ $\mathrm{Cl}^{-}$. This interfacial chloride concentration can be expected to drop to even lower values at mass transfer-limiting conditions for the CER. While some corrosion of OER electrocatalysts is still possible at millimolar chloride concentrations, corrosion will be significantly attenuated at these concentrations. By contrast, unencapsulated anodes composed of mixed metal oxides of $\mathrm{Ni}, \mathrm{Co}$, and $\mathrm{Fe}$ have demonstrated stability for up to days during OER operation in chloride concentrations of up to $4 \mathrm{M}^{7,14,19,20,67}$ Importantly, the $\mathrm{SiO}_{x}$ overlayer may also help prevent leaching of metal cations produced by the dissolution of the electrocatalyst by blocking these cations' transport out from the buried interface. $\mathrm{SiO}_{x}$ overlayers have been previously shown to selectively reject aqueous $\mathrm{Cu}^{2+}$ ion transport, ${ }^{53}$ and similar overlayer selectivity with other metal cations could minimize the rate of electrocatalyst corrosion. To further reduce the chloride concentration at the buried interface, anionic fixed charges could be incorporated into the $\mathrm{SiO}_{x}$ overlayer to electrostatically repel $\mathrm{Cl}^{-}$. These considerations suggest that the risk of chloride corrosion of $\mathrm{SiO}_{x}$-encapsulated anodes is manageable. Aside from its implications for corrosion, the indications of low chloride concentrations at the buried interface suggest that $\mathrm{SiO}_{x} \mid \mathrm{Pt}$ may also suppress the $\mathrm{CER}$, as discussed in the following section.

2.2. Evaluating Transport Properties of $\mathrm{SiO}_{x}$ Overlayers. To further investigate the ability of the overlayer to suppress the CER at more positive potentials relevant to the OER, linear sweep voltammetry (LSV) was performed in chloride-containing and chloride-free electrolytes under both unbuffered $\mathrm{pH}$-neutral and acidic conditions. In the absence of chloride ions, the CER does not occur, allowing for an isolated view of OER activity. In the chloride-free supporting electrolyte at acidic $\mathrm{pH}$ (Figure $3 \mathrm{a}$ ), the $4.8 \mathrm{~nm} \mathrm{SiO}_{x} \mid \mathrm{Pt}$ electrodes show an onset potential for the OER of $\approx 1.6 \mathrm{~V}$ vs RHE, which is nearly identical to the OER onset for bare Pt. Some suppression of the OER signal is seen for the $\mathrm{SiO}_{x}$ encapsulated electrodes, which becomes more pronounced as the $\mathrm{SiO}_{x}$ thickness increases (Figure S3a). In the presence of $0.6 \mathrm{M} \mathrm{KCl}$ at low $\mathrm{pH}$ (Figure $3 \mathrm{~b}$ ), bare Pt shows a CER onset potential located $270 \mathrm{mV}$ more negative than the OER onset potential seen in the supporting electrolyte, reaching a maximum total current density of $\approx 160 \mathrm{~mA} \mathrm{~cm}{ }^{-2}$ at the vertex potential of $1.90 \mathrm{~V}$ vs RHE (Figure S4). Under the same conditions, $\mathrm{SiO}_{x} \mathrm{Pt}$ exhibits dramatically suppressed CER activity, maintaining current densities below $0.15 \mathrm{~mA} \mathrm{~cm}{ }^{-2}$ at potentials negative of the OER onset identified in Figure $3 \mathrm{a}$. For $\mathrm{SiO}_{x} \mid \mathrm{Pt}$ in the saline electrolyte, the increase in current density recorded positive of the OER onset potential closely mirrors the OER behavior of $\mathrm{SiO}_{x} \mathrm{Pt}$ in the supporting electrolyte. This is confirmed by closer inspection of the low current density region of the overlaid LSV curves for the 4.8 $\mathrm{nm} \mathrm{SiO}_{x} \mathrm{IPt}$ LSV curves in the supporting and saline electrolytes, which are provided in Figure $3 \mathrm{c}$. 
(a)

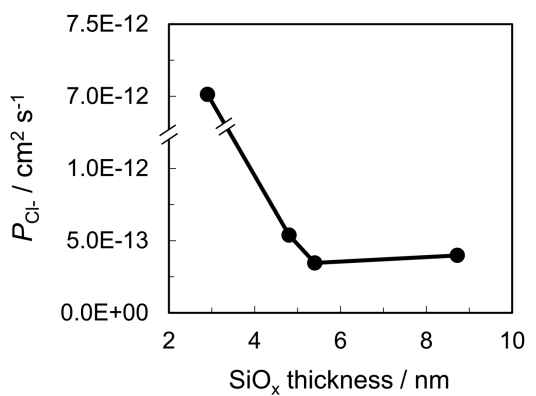

(b)

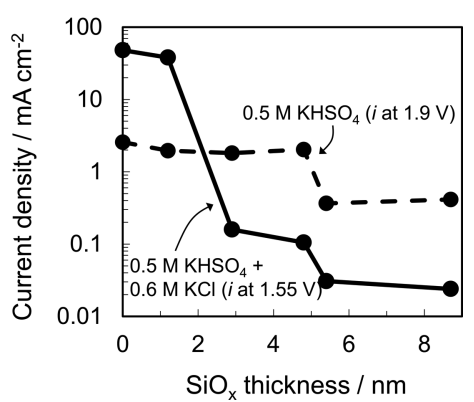

Figure 4. (a) Permeability of $\mathrm{Cl}^{-}$in $\mathrm{SiO}_{x}$ overlayers as a function of overlayer thickness, calculated from $\mathrm{LSVs}_{\mathrm{s}}$ for $\mathrm{SiO}_{x} \mathrm{Pt}$ in $0.5 \mathrm{M} \mathrm{KHSO}_{4}+0.6 \mathrm{M}$ $\mathrm{KCl}$ using eq 4. (b) Current densities for $\mathrm{SiO}_{x} \mathrm{Pt}$ recorded at $+1.90 \mathrm{~V}$ vs RHE during LSVs in $0.5 \mathrm{M} \mathrm{KHSO}_{4}$ (dashed curve) and recorded at +1.55 $\mathrm{V}$ vs RHE during LSVs in $0.5 \mathrm{M} \mathrm{KHSO}_{4}+0.6 \mathrm{M} \mathrm{KCl}$ (solid curve).

The LSV curves in Figure $3 c$ indicate that most of the oxidation current observed for the $4.8 \mathrm{~nm} \mathrm{SiO} \mathrm{S}_{x} \mid \mathrm{Pt}$ electrode in the saline electrolyte at potentials more positive than $1.6 \mathrm{~V}$ vs RHE is contributed by the OER rather than the CER. The enlarged view provided by the order-of-magnitude shorter vertical axis in Figure $3 c$ reveals slightly elevated current densities compared to those measured in the supporting electrolyte, indicating that a very small amount of the CER still takes place on $4.8 \mathrm{~nm} \mathrm{SiO} \mathrm{S}_{x} \mathrm{Pt}$. Thanks to the large disparity in the OER and CER onset potentials, the difference curve between the chloride-containing and chloride-free LSVs for 4.8 $\mathrm{nm} \mathrm{SiO}{ }_{x} \mathrm{Pt}$ (Figure S5) clearly reveals the presence of a low mass transfer-limiting CER current density of $\approx 0.05 \mathrm{~mA} \mathrm{~cm}{ }^{-2}$ at potentials negative of $1.60 \mathrm{~V}$ vs RHE without interference from the OER.

Assuming that $\mathrm{Cl}^{-}$transport occurs only by diffusion through a continuous and uniform $\mathrm{SiO}_{x}$ overlayer to a planar Pt electrode, Faraday's law and Fick's law can be used to describe the steady-state flux of $\mathrm{Cl}^{-}$to the electrode surface at mass transfer-limiting conditions for each $\mathrm{SiO}_{x}$ thickness. These equations relate the limiting current densities at steady state $\left(i_{\text {lim }}\right)$ to the concentration of chloride ions at the interface between the $\mathrm{SiO}_{x}$ overlayer and the bulk electrolyte $\left(C_{\mathrm{Cl}^{-}}(x=\right.$ $\left.t_{0}\right)$ ), and the chloride permeability $\left(P_{\mathrm{Cl}^{-}}\right)$within the overlayer (eq 4)

$$
i_{\mathrm{lim}, \mathrm{CER}}=n \cdot F \cdot P_{\mathrm{Cl}^{-}} \cdot \frac{C_{\mathrm{Cl}^{-}}\left(x=t_{0}\right)}{t_{0}}
$$

where $n$ is the stoichiometric number of electrons, $F$ is the Faraday constant, and $t_{0}$ is the thickness of the $\mathrm{SiO}_{x}$ overlayer. For large bulk chloride concentrations such as that used in this study, it can be assumed that the $\mathrm{Cl}^{-}$concentration gradient across the bulk diffusion boundary layer is insignificant at low current densities, meaning that $C_{\mathrm{Cl}^{-}}\left(x=t_{0}\right)$ is equal to the bulk chloride concentration. Based on the $\mathrm{SiO}_{x}$ thicknesses measured by ellipsometry and the CER limiting current densities observed in LSV measurements, eq 4 gives $P_{\mathrm{Cl}^{-}}$values in the range of $\left(3 \times 10^{-13}\right)-\left(6 \times 10^{-13}\right) \mathrm{cm}^{2} \mathrm{~s}^{-1}$ for $4.8-8.7$ $\mathrm{nm}$ thick $\mathrm{SiO}_{x}$ overlayers (Figure 4a). These values are 8 orders of magnitude lower than the bulk diffusivity of $\mathrm{Cl}^{-}$in aqueous solutions ${ }^{68}$ and 3 orders of magnitude lower than the permeability of $\mathrm{Cl}^{-}$in aromatic polyamide, ${ }^{69}$ a salt-selective membrane material used in reverse osmosis water desalination.

Nearly identical $\mathrm{Cl}^{-}$-blocking behavior is observed in LSV curves for $4.8 \mathrm{~nm} \mathrm{SiO}{ }_{x} \mid \mathrm{Pt}$ recorded in unbuffered $\mathrm{pH}$-neutral electrolyte with and without chloride ions (Figure S6). These LSVs show marked suppression of the CER in the presence of
0.6 $\mathrm{M} \mathrm{Cl}^{-}$and minimal suppression of the OER in the supporting electrolyte for $4.8 \mathrm{~nm} \mathrm{SiO}_{x} \mid \mathrm{Pt}$ compared to that for bare $\mathrm{Pt}$ at neutral $\mathrm{pH}$, demonstrating the selectivity of the overlayer for the OER in unbuffered $\mathrm{pH}$-neutral conditions in addition to acidic media.

These LSV curves demonstrating CER suppression on $\mathrm{SiO}_{x} \mathrm{I}$ $\mathrm{Pt}$ are also reproducible in the acidic chloride-containing electrolyte that uses $\mathrm{Na}^{+}$as the cation instead of $\mathrm{K}^{+}$(Figure S7), relevant because $\mathrm{Na}^{+}$is the predominant cation in natural seawater. In an $\mathrm{LSV}$ in $0.5 \mathrm{M} \mathrm{H}_{2} \mathrm{SO}_{4}+0.6 \mathrm{M} \mathrm{NaCl}, 4.8 \mathrm{~nm}$ $\mathrm{SiO}_{x} \mid \mathrm{Pt}$ displays low current densities of $\approx 0.1 \mathrm{~mA} \mathrm{~cm}{ }^{-2}$ at potentials negative of $1.6 \mathrm{~V}$ vs RHE due to CER suppression and increasing current densities positive of $1.6 \mathrm{~V}$ vs RHE due to the onset of the OER. In contrast, the bare Pt electrode in the $\mathrm{Na}^{+}$-containing electrolyte shows a large CER current with an onset potential of $1.3 \mathrm{~V}$ vs RHE, mirroring our results for bare $\mathrm{Pt}$ in the $\mathrm{K}^{+}$-containing electrolyte. The strong agreement between LSVs in the presence of $\mathrm{K}^{+}$and $\mathrm{Na}^{+}$suggests that our results using $\mathrm{K}^{+}$are applicable to electrolysis of $\mathrm{Na}^{+}$-rich natural seawater.

Additional LSV curves using $\mathrm{SiO}_{x}$ overlayers of varied thickness in $0.5 \mathrm{M} \mathrm{KHSO}_{4}$ and $0.5 \mathrm{M} \mathrm{KHSO}_{4}+0.6 \mathrm{M} \mathrm{KCl}$ (Figure S3) demonstrate that there is a narrow range of $\mathrm{SiO}_{x}$ thicknesses for which the CER signal is greatly suppressed without also substantially decreasing the OER signal. This is summarized in Figure $4 \mathrm{~b}$, which, as a function of overlayer thickness, plots the current density at $1.55 \mathrm{~V}$ vs RHE from LSVs in the acidic chloride solution as a measure of the ability of $\mathrm{SiO}_{x}$ to block $\mathrm{Cl}^{-}$transport (solid curve) and the current density at $1.90 \mathrm{~V}$ vs RHE from LSVs in the supporting electrolyte as a measure of the ability to permit species transport associated with the OER (dashed curve). This figure shows that $\mathrm{SiO}_{x}$ overlayer thickness of $\approx 3 \mathrm{~nm}$ or more is needed to suppress the CER, but making the overlayer much thicker than $4.8 \mathrm{~nm}$ also leads to a significant decrease in the desired OER current density.

The estimated faradic efficiency (FE) of $\mathrm{SiO}_{x} \mid \mathrm{Pt}$ for the OER further illustrates the thickness-dependent performance of the $\mathrm{SiO}_{x}$ overlayers. The FE was estimated from saline LSVs by linearly extrapolating the CER mass transfer-limiting current region that appears negative of the OER onset and assuming all additional current arises from the OER. This method is depicted in Figure S8a, and the FE of 2.9-8.7 nm $\mathrm{SiO}_{x} \mid \mathrm{Pt}$ as a function of potential is shown in Figure $S 8 b ; 4.8 \mathrm{~nm} \mathrm{SiO}{ }_{x} \mid \mathrm{Pt}$ has the highest $\mathrm{FE}$ compared to thicker and thinner $\mathrm{SiO}_{x}$ overlayers for all potentials positive of $1.6 \mathrm{~V}$ vs RHE and reaches a maximum $\mathrm{FE}$ of $85 \%$ toward the OER at $1.90 \mathrm{~V}$ vs 
RHE. The FE values of all $\mathrm{SiO}_{x} \mid \mathrm{Pt}$ electrodes are greatly increased compared to that of bare $\mathrm{Pt}$, which reaches a maximum $\mathrm{FE}$ of $1.6 \%$ at $1.90 \mathrm{~V}$ vs $\mathrm{RHE}$, once again demonstrating the high selectivity of the $\mathrm{SiO}_{x} \mid \mathrm{Pt}$ electrocatalysts for the OER over the CER.

The selectivity of the $\mathrm{SiO}_{x}$ overlayer for the OER over the CER is particularly notable considering the unfavorable conditions for the OER in this study, which involved a poor OER electrocatalyst $(\mathrm{Pt})$ while using large $\mathrm{Cl}^{-}$concentrations in an acidic environment. Compared to previous studies in acidic conditions that have used lower chloride concentrations, ${ }^{31,43}$ the $0.6 \mathrm{M}$ chloride concentration used here presents a significantly greater challenge to achieving high OER selectivity. Additionally, we expect that the application of $\mathrm{Sio}_{x}$ overlayers to more active OER electrocatalysts will allow for significant increases in OER faradic efficiencies over the same potential range studied here, for which Pt exhibits very low OER partial current densities. The $\mathrm{FE}$ of $\mathrm{SiO}_{x} \mathrm{IPt}$ for the OER should thus be viewed in the context of the combination of disadvantages overcome to achieve it.

In addition to rejecting $\mathrm{Cl}^{-}$, the $\mathrm{SiO}_{x}$ overlayer must allow $\mathrm{O}_{2}$ and $\mathrm{H}^{+}$to escape through the overlayer as they are evolved at the buried interface during the OER, to reduce OER concentration overpotentials. In a separate recent study from our group, ${ }^{56}$ the $\mathrm{O}_{2}$ and $\mathrm{H}^{+}$permeabilities $\left(P_{\mathrm{O}_{2}}\right.$ and $\left.P_{\mathrm{H}^{+}}\right)$of $\mathrm{SiO}_{x}$ overlayers were determined from the mass transferlimiting current densities associated with the oxygen reduction reaction (ORR) and hydrogen evolution reaction (HER), respectively. For $\mathrm{SiO}_{x}$ overlayers with comparable thicknesses and identical UV-ozone treatment to those used in this study, $P_{\mathrm{O}_{2}}$ and $P_{\mathrm{H}^{+}}$were reported to be $(2.1 \pm 0.6) \times 10^{-9}$ and $(1.0 \pm$ $0.5) \times 10^{-7} \mathrm{~cm}^{2} \mathrm{~s}^{-1}$, respectively. These values are 4-6 orders of magnitude greater than the values of $P_{\mathrm{Cl}^{-}}$found in this study, indicating that the overlayer does not suppress the transport of $\mathrm{O}_{2}$ and $\mathrm{H}^{+}$to the same extent that it does for $\mathrm{Cl}^{-}$. While the $\mathrm{Pt}$ electrocatalyst substrate used in these experiments was significantly thicker than that used herein, which has been known to cause changes to $\mathrm{SiO}_{x}$ overlayer permeabilities, ${ }^{52}$ these changes are not expected to span orders of magnitude. The relatively high $P_{\mathrm{O}_{2}}$ and $\mathrm{P}_{\mathrm{H}^{+}}$of $\mathrm{SiO}_{x}$ overlayers will promote the transport of $\mathrm{O}_{2}$ and $\mathrm{H}^{+}$away from the buried interface, helping to reduce OER concentration overpotentials. Higher values of $P_{\mathrm{O}_{2}}$ are also expected to be beneficial for mitigating the formation of $\mathrm{O}_{2}$ gas nanobubbles at nanoscopic voids at the buried interface, where they could facilitate overlayer delamination. Due to the unfavorable energetics of $\mathrm{O}_{2}$ nanobubble formation, dissolved $\mathrm{O}_{2}$ concentrations orders of magnitude greater than the equilibrium $\mathrm{O}_{2}$ saturation concentration may be required to nucleate nanobubbles. ${ }^{70}$ Overlayers characterized by high $P_{\mathrm{O}_{2}}$ are expected to result in lower concentrations of dissolved $\mathrm{O}_{2}$ within the overlayer, reducing the likelihood of nanobubble nucleation.

2.3. Stability of $\mathrm{SiO}_{x} \mathrm{Pt}$ Electrodes. In addition to characterizing the selective transport properties of $\mathrm{SiO}_{x}$ overlayers, the stability of $\mathrm{SiO}_{x}$-encapsulated electrodes was investigated using chronoamperometry (CA) tests conducted at 1.55 and $1.90 \mathrm{~V}$ vs RHE in the $0.5 \mathrm{M} \mathrm{KHSO}_{4}(+0.6 \mathrm{M} \mathrm{KCl})$ electrolyte. A potential of $1.55 \mathrm{~V}$ vs RHE was chosen because it lies in between the CER and OER onset potentials seen for bare Pt in Figure 3a,b, respectively. Thus, CA measurements performed at $1.55 \mathrm{~V}$ vs RHE in low $\mathrm{pH}$ (Figure 5a,c) provide sufficient overpotential for the CER, but not the OER, to occur on Pt. An applied potential of $1.90 \mathrm{~V}$ vs RHE (Figure 5b,d) then provides a large enough overpotential for both reactions to occur on $\mathrm{Pt}$.

CA curves measured at $1.55 \mathrm{~V}$ vs RHE in the chloride-free supporting electrolyte are provided in Figure 5a, where it is seen that the pseudo-steady-state current densities of both bare $\mathrm{Pt}$ and $4.8 \mathrm{~nm} \mathrm{SiO}_{x} \mid \mathrm{Pt}$ electrodes are well below $10 \mu \mathrm{A} \mathrm{cm}^{-2}$. This result is consistent with the fact that there is little to no OER activity on the Pt electrodes at this potential. The very small oxidation currents that are observed likely result from $\mathrm{Pt}$ oxidation, where the growth of insoluble $\mathrm{PtO}_{x}$ at the $\mathrm{Pt}$ surface proceeds logarithmically in time but does not reach a saturation point under the conditions of this study. ${ }^{52,58,59,71}$ Interestingly, the integrated charge passed by the bare $\mathrm{Pt}$ electrode after $30 \mathrm{~min}$ is 4 times greater than that for the 4.8 $\mathrm{nm} \mathrm{SiO}_{x} \mid \mathrm{Pt}$ electrode. Assuming that all of the current passed was associated with the oxidation of $\mathrm{Pt}$, this finding suggests that the $\mathrm{SiO}_{x}$ overlayer serves as a sort of artificial passive oxide that helps to suppress $\mathrm{Pt}$ dissolution and/or limit the rate of $\mathrm{PtO}_{x}$ formation at the $\mathrm{SiO}_{x} \mathrm{Pt}$ buried interface. Further investigations are needed to test this hypothesis, but the proposed explanation is supported by our previous studies showing that $\mathrm{SiO}_{x}$ overlayers are effective diffusion barriers for $\mathrm{Cu}^{2+}$ ions. ${ }^{52,53}$

Upon increasing the applied potential to $1.90 \mathrm{~V}$ vs RHE in the supporting electrolyte (Figure $5 \mathrm{~b}$ ), the oxidation current densities increase by $1-2$ orders of magnitude, which we attribute to the presence of the OER. After recording initial peak current densities of 7.4 and $1.0 \mathrm{~mA} \mathrm{~cm}{ }^{-2}$ at the start of the CA measurements for bare $\mathrm{Pt}$ and $4.8 \mathrm{~nm} \mathrm{SiO}_{x} \mid \mathrm{Pt}$, respectively, the current densities rapidly decrease over the first $\approx 1 \mathrm{~h}$. Then, the current densities more gradually decrease over the remaining $11 \mathrm{~h}$ to final values of 0.07 and $0.02 \mathrm{~mA} \mathrm{~cm}$ for bare $\mathrm{Pt}$ and $4.8 \mathrm{~nm} \mathrm{SiO} \mathrm{I}_{\mathrm{Pt}} \mathrm{Pt}$, respectively. These observed decreases in current densities most likely result from the formation of the aforementioned $\mathrm{PtO}_{x}$ surface species, which are known to have lower catalytic activity for the OER and the CER compared to metallic Pt. ${ }^{58,72,73}$

When CA experiments were repeated for identical freshly prepared electrodes in the presence of $0.6 \mathrm{M} \mathrm{KCl}$, the presence of the CER led to significant increases in current densities for $\mathrm{CA}$ tests at $1.55 \mathrm{~V}$ vs RHE (Figure 5c) and $1.90 \mathrm{~V}$ vs RHE (Figure $5 \mathrm{~d}$ ). After $12 \mathrm{~h}$ of operation, bare Pt held at $1.55 \mathrm{~V}$ vs RHE exhibits the largest pseudo-steady-state current density $\left(\approx 10 \mathrm{~mA} \mathrm{~cm}{ }^{-2}\right)$, while the $4.8 \mathrm{~nm} \mathrm{SiO}{ }_{x} \mid \mathrm{Pt}$ electrode records the smallest current density $\left(\approx 0.02 \mathrm{~mA} \mathrm{~cm}{ }^{-2}\right)$. Further, the $\mathrm{CA}$ for the $\mathrm{SiO}_{x} \mid \mathrm{Pt}$ electrode displays no increase in current density over $12 \mathrm{~h}$ of operation, highlighting the ability of the $\mathrm{SiO}_{x}$ overlayer to achieve a high degree of CER suppression over long time periods in high chloride concentrations and acidic environment.

In the saline electrolyte at $1.90 \mathrm{~V}$ vs RHE (Figure 5d), bare Pt shows substantial current density, although it is lower than current densities recorded at $1.55 \mathrm{~V}$ vs RHE. As previously reported, the decreased CER current on bare $\mathrm{Pt}$ at very positive potentials can be attributed to the increased growth of $\mathrm{PtO}_{x}$ surface species that inhibit CER kinetics. ${ }^{58,72,73}$ By contrast, the CA curve for the $4.8 \mathrm{~nm} \mathrm{SiO} x \mid \mathrm{Pt}$ electrode in the saline electrolyte at $1.90 \mathrm{~V}$ vs RHE shows an increased current density compared to that recorded in the chloride-free supporting electrolyte at $1.90 \mathrm{~V}$ vs RHE. This increase suggests that the CER is able to occur to a greater extent at 
(a)

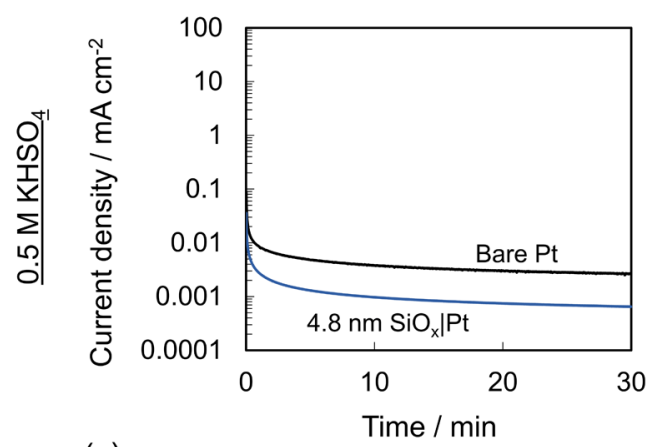

(c)

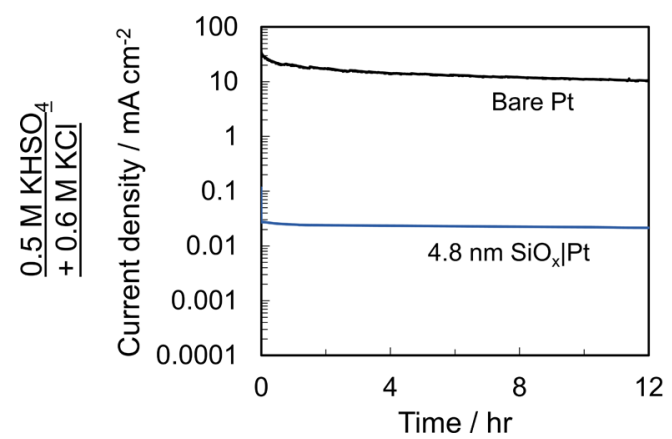

(b)

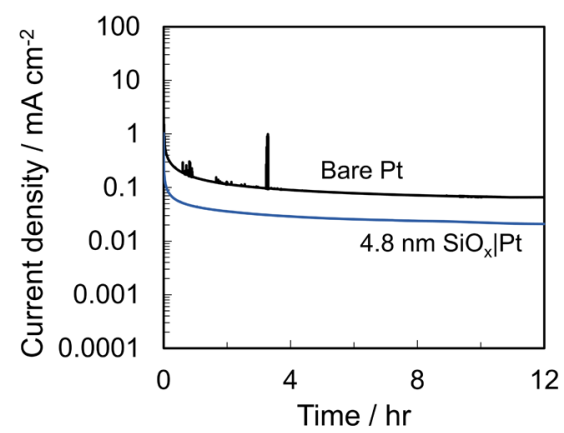

(d)

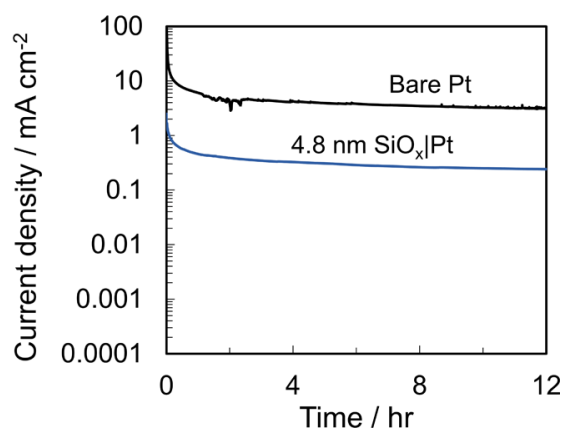

Figure 5. CA stability measurements for bare Pt and $4.8 \mathrm{~nm} \mathrm{SiO} \mathrm{IPt}_{\mathrm{I}} \mathrm{Pt} .5 \mathrm{M} \mathrm{KHSO}_{4}$ at constant applied potentials of (a) $1.55 \mathrm{~V}$ vs $\mathrm{RHE}$ and (b) $1.90 \mathrm{~V}$ vs RHE. $12 \mathrm{~h} \mathrm{CA}$ stability measurements for bare Pt and $4.8 \mathrm{~nm} \mathrm{SiO} \mathrm{St}_{x} \mathrm{Pt}$ in $0.5 \mathrm{M} \mathrm{KHSO}_{4}+0.6 \mathrm{M} \mathrm{KCl}$ at constant applied potentials of (c) $1.55 \mathrm{~V}$ vs RHE and (d) $1.90 \mathrm{~V}$ vs RHE. All measurements were performed in deaerated electrolyte at pH 0.8 and $25^{\circ} \mathrm{C}$.

$1.90 \mathrm{~V}$ vs RHE than at $1.55 \mathrm{~V}$ vs $\mathrm{RHE}$ on $\mathrm{SiO}_{x} \mid \mathrm{Pt}$. However, the fact that the current density for $\mathrm{SiO}_{x} \mid \mathrm{Pt}$ remains stable at more than an order of magnitude lower than that observed for the bare Pt electrode attests to the ability of the $\mathrm{SiO}_{x}$ overlayer to greatly suppress the CER even under large operating overpotentials ( $\approx 600 \mathrm{mV}$ vs $\left.E_{\mathrm{Cl}^{-} / \mathrm{Cl}_{2}}^{0}\right)$.

While it is possible that the higher current density at $1.90 \mathrm{~V}$ could result from elevated $\mathrm{Cl}^{-}$migration rates across the overlayer thanks to a higher electric field strength at the electrode-electrolyte interface, mechanical instability of the $\mathrm{SiO}_{x}$ overlayer may also be responsible. Some evidence for overlayer degradation/delamination is observed in the earliest portion of the $1.90 \mathrm{~V}$ vs RHE CA curve (Figure S9), where an initial gradual decay in current density is interrupted by a multistep increase in current from $t=12$ to $54 \mathrm{~s}$. While the current density then decreases gradually without similar interruptions beyond this point, the initial increase in current density yields a higher steady-state current density than would have otherwise occurred. The same feature is absent from the early time periods of the CA curves recorded at 1.55 and 1.90 $\mathrm{V}$ vs RHE in the supporting electrolyte.

To investigate the physical stability of the $\mathrm{SiO}_{x}$ overlayers, ellipsometry, X-ray photoelectron spectroscopy (XPS), and scanning electron microscopy (SEM) characterization measurements were performed on $4.8 \mathrm{~nm} \mathrm{SiO}_{x} \mid \mathrm{Pt}$ electrodes before and after the $12 \mathrm{~h} \mathrm{CA}$ tests in the saline electrolyte. SEM images of the as-made $\mathrm{SiO}_{x} \mid \mathrm{Pt}$ samples before each stability test show a smooth, continuous $\mathrm{SiO}_{x}$ surface with minimal defects (Figure 6a,b, left). After the $12 \mathrm{~h} \mathrm{CA}$ test at $1.55 \mathrm{~V}$ vs RHE in the saline electrolyte (Figure 5c), SEM shows darkcolored micron-scale features covering a small fraction of the surface (Figure 6a, right), which we ascribe to debris accumulated on the sample during testing and handling. The
$\mathrm{SiO}_{x}$ overlayer otherwise displays minimal degradation after the CA at $1.55 \mathrm{~V}$ vs RHE.

Importantly, XPS Si $2 p$ spectra showed that $\mathrm{SiO}_{x}$ was still present on the electrode surface following the $12 \mathrm{~h}$ CAs in the saline electrolyte at both 1.55 and $1.90 \mathrm{~V}$ vs RHE (Figure 6c). The $4.8 \mathrm{~nm} \mathrm{SiO}_{x} \mid \mathrm{Pt}$ sample tested at $1.55 \mathrm{~V}$ vs RHE appears unchanged in SEM images taken post-CA (Figure 6a, right) and demonstrates only a $2 \%$ reduction in the atomic $\mathrm{Si} / \mathrm{Pt}$ signal ratio as measured by XPS (Figure 6d), corroborating the overlayer's stability in this test. In contrast, the $4.8 \mathrm{~nm} \mathrm{SiO} \mathrm{S}_{x} \mathrm{Pt}$ electrode characterized by SEM after the stability test at $1.90 \mathrm{~V}$ vs RHE displays cracking and delamination of the $\mathrm{SiO}_{x}$ overlayer (Figure $6 \mathrm{~b}$, right) and a $40 \%$ reduction in the atomic Si/Pt signal ratio (Figure 6d). While some of the damage to the $\mathrm{SiO}_{x}$ overlayer could have been incurred upon rinsing and drying of the sample after removal from the electrochemical test cell, it is likely that some degree of overlayer instability had already developed during the CA test and may explain the increased CER current for the $4.8 \mathrm{~nm}$ $\mathrm{SiO}_{x} \mathrm{Pt}$ electrode in the CA at $1.90 \mathrm{~V}$ vs RHE. We postulate that the overlayer's mechanical integrity was partially compromised $12 \mathrm{~s}$ into the $\mathrm{CA}$, creating the aforementioned increase in current observed at that time in Figure S9. After this initial perturbation, the continuous decline in current density throughout the remainder of the CA suggests that further damage to the overlayer was limited.

Although additional experimentation is needed to confirm the origin of the damage caused to the $4.8 \mathrm{~nm} \mathrm{SiO}{ }_{x}$ overlayers during operation at $1.90 \mathrm{~V}$ vs $\mathrm{RHE}$, it is likely that thicker $\mathrm{PtO}_{x}$ interlayers formed between $\mathrm{Pt}$ and $\mathrm{SiO}_{x}$ at such positive applied potentials could be a contributing factor. This interlayer-mediated degradation mechanism is supported by our prior study on $\mathrm{SiO}_{x}$-encapsulated $\mathrm{Pt}$ thin films that found 
(a)

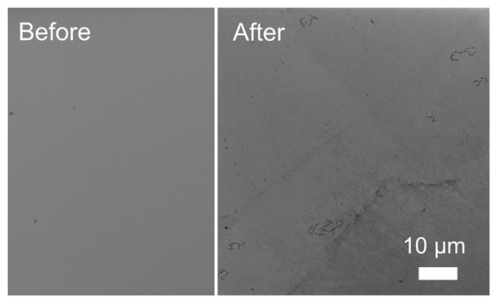

(c)

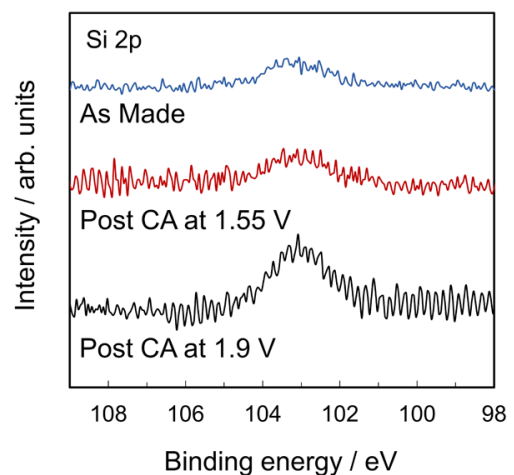

(b)

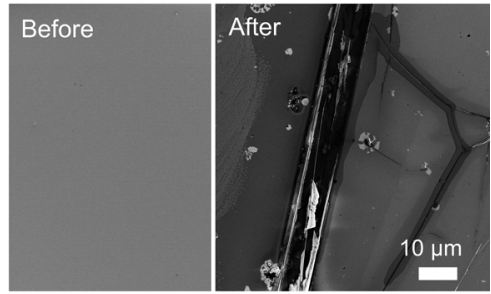

(d)

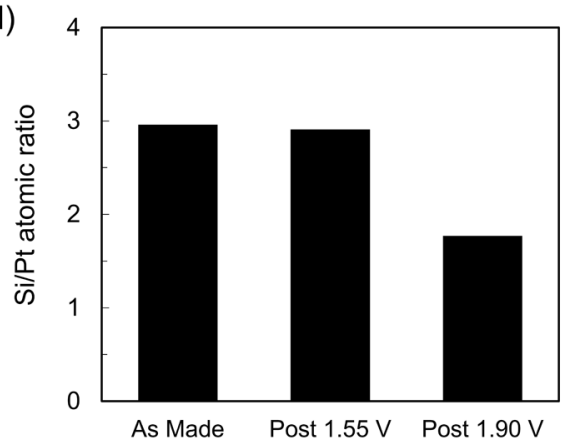

Figure 6. SEM images of $4.8 \mathrm{~nm} \mathrm{SiO}_{x} / \mathrm{Pt}$ before (left) and after (right) $12 \mathrm{~h} \mathrm{CA}$ in $0.5 \mathrm{M} \mathrm{KHSO}_{4}+0.6 \mathrm{M} \mathrm{KCl}$ at (a) $1.55 \mathrm{~V}$ vs RHE and (b) $1.90 \mathrm{~V}$ vs RHE. (c) XPS Si 2p spectra for $4.8 \mathrm{~nm} \mathrm{SiO}{ }_{x} \mathrm{Pt}$ electrodes as-made and post-CA and (d) $\mathrm{Si} / \mathrm{Pt}$ atomic ratio for as-made and post-CA samples. CAs performed in $0.5 \mathrm{M} \mathrm{KHSO}_{4}+0.6 \mathrm{M} \mathrm{KCl}$ electrolyte for a duration of $12 \mathrm{~h}$. Potentials provided in the subfigures are given vs the RHE.

that $\mathrm{SiO}_{x} \mid \mathrm{Pt}$ electrodes subjected to $\mathrm{CV}$ cycling over potential ranges extending to potentials more positive than the $\mathrm{Pt}$ oxidation onset potential exhibited accelerated delamination compared to those cycled over a narrow potential range that remained below the $\mathrm{PtO}_{x}$ onset potential. ${ }^{52}$ Since $\mathrm{PtO}_{x}$ overlayers grow faster and to thicker values at more positive potentials, ${ }^{58,73}$ and $\mathrm{PtO}_{x}$ is less dense than $\mathrm{Pt}$, the formation and expansion of a thicker $\mathrm{PtO}_{x}$ interlayer at $1.90 \mathrm{~V}$ vs RHE could create more interfacial stress with the $\mathrm{SiO}_{x}$ overlayer, causing the cracking and partial delamination observed in Figure $6 \mathrm{~b}$. Since an increase in current density was observed at the outset of the CA at $1.90 \mathrm{~V}$ vs RHE in saline but not in the supporting electrolyte, it is possible that interactions between $\mathrm{Cl}^{-} / \mathrm{Cl}_{2}$ and $\mathrm{SiO}_{x} \mid \mathrm{Pt}$, or the higher current densities observed in the saline electrolyte, could play an additional role in $\mathrm{SiO}_{x}$ overlayer instability when operated at very positive applied potentials.

Despite the partial delamination observed during extended CA measurements at $1.90 \mathrm{~V}$ vs RHE, there are several reasons to remain optimistic that $\mathrm{SiO}_{x}$ overlayers can remain stable under industrially relevant conditions. First, the $\mathrm{SiO}_{x}$ overlayer shows no signs of degradation over $12 \mathrm{~h}$ at $1.55 \mathrm{~V}$ vs RHE in the acidic electrolyte with $0.6 \mathrm{M} \mathrm{Cl}^{-}$. While the overlayer does exhibit some degradation at $1.90 \mathrm{~V}$ vs RHE, there is good reason to believe that this instability is associated with oxidation of the underlying $\mathrm{Pt}$ electrocatalyst rather than (electro)chemical instability of the overlayer itself. This degradation mechanism may be avoided through the use of active OER electrocatalysts that have strong adhesive interactions with $\mathrm{SiO}_{x}$ and are not susceptible to the formation of interlayers that can create detrimental interfacial stresses. Further, high-surface-area electrode designs based on supported electrocatalytic nanoparticles will contain catalytically inert support material to which $\mathrm{SiO}_{x}$ overlayers may become anchored without any stress-inducing OER chemistry occurring at the $\mathrm{SiO}_{x}$ lsupport interface. Takenaka et al. have shown that $\mathrm{SiO}_{2}$-encapsulated $\mathrm{Pt}$ nanoparticles supported on highsurface-area carbon-based supports for the oxygen reduction reaction (ORR) can exhibit excellent durability over 20000 cycles of $\mathrm{CV},^{74,75}$ a result that bodes well for the use of similar encapsulated electrocatalyst architectures for other applications like the OER

2.4. Mechanisms of Selective Transport through $\mathrm{SiO}_{x}$ Overlayers. A deeper understanding of the transport mechanisms through amorphous silicon oxide overlayers is necessary to explain their ability to selectively block $\mathrm{Cl}^{-}$ions and to guide the design of optimized $\mathrm{SiO}_{x}$-encapsulated electrodes for seawater electrolysis. Several recent studies of $\mathrm{SiO}_{x}$-encapsulated $\mathrm{Pt}$ electrodes have given insights into $\mathrm{H}^{+}$ and $\mathrm{O}_{2}$ transport through $\mathrm{SiO}_{x}$ overlayers, ${ }^{41,56,76}$ but overall, little is known about the structure-property relationships of oxide-encapsulation layers that dictate trends in permeabilities across various types of electroactive species. To gain further insight into the origins of the low chloride permeability of $\mathrm{SiO}_{x}$ overlayers, we investigated the ability of $\mathrm{SiO}_{x}$ overlayers to similarly block $\mathrm{Br}^{-}$ions as measured by monitoring the bromine evolution reaction (BER, eq 5)

$$
2 \mathrm{Br}^{-} \rightarrow \mathrm{Br}_{2}+2 \mathrm{e}^{-} ; E^{0}=1.07 \mathrm{~V} \text { vs NHE }
$$

The BER was selected for additional measurements because it is similar in many ways to the CER, with identical stoichiometry and similar standard reduction potentials, fast two-electron kinetics, and reactant species that are both monatomic, monovalent anions. The primary differences are that $\mathrm{Br}^{-}$has a larger bare ion radius and lower hydration energy than $\mathrm{Cl}^{-} \cdot{ }^{-7}-79$ Thus, a comparison of chloride and bromide permeabilities determined from CER and BER measurements, respectively, can give insights into the importance of permeant size and/or hydration energy on species flux and transport mechanism(s). The permeability of $\mathrm{Br}^{-}\left(P_{\mathrm{Br}^{-}}\right)$through $\approx 5 \mathrm{~nm}$ thick $\mathrm{SiO}_{x}$ overlayers was determined from analysis of LSV curves measured with bare 
$\mathrm{Pt}$ and $4.8 \mathrm{~nm} \mathrm{SiO} \mathrm{n}_{x} \mathrm{Pt}$ in $0.5 \mathrm{M} \mathrm{KHSO}_{4}+20 \mathrm{mM} \mathrm{KBr}$ (Figure $\mathrm{S} 10)$ to probe the BER on $\mathrm{SiO}_{x}$-encapsulated electrodes. The calculation of $\mathrm{P}_{\mathrm{Br}}{ }^{-}$followed the procedure described by Beatty et al., ${ }^{56}$ with an abbreviated description and list of equations included in Section XI, Supporting Information. Through this calculation, $P_{\mathrm{Br}^{-}}$was determined to be $1.4 \times 10^{-11} \mathrm{~cm}^{2} \mathrm{~s}^{-1}$. This value is roughly 2 orders of magnitude larger than the calculated $P_{\mathrm{Cl}^{-}}$value of $5.4 \times 10^{-13} \mathrm{~cm}^{2} \mathrm{~s}^{-1}$ for $4.8 \mathrm{~nm} \mathrm{SiO} \mathrm{S}_{x} \mathrm{Pt}$, meaning that $\mathrm{Br}^{-}$transport in the $\mathrm{SiO}_{x}$ overlayer is significantly faster than that of $\mathrm{Cl}^{-}$.

Borrowing concepts from transport theory across dense films widely employed in synthetic membranes, there are several possible explanations for the large differences between $P_{\mathrm{Br}^{-}}$and $P_{\mathrm{Cl}^{-}}$that rely on understanding how a solute species interacts with the membrane or overlayer material and how those interactions depend on the structure and composition of both the membrane and solute. Here, we consider several different explanations, providing evidence and logic for and against each.

The first possible explanation is steric size exclusion on the basis of the hydrated radii of solute species, whereby a solute encounters a barrier to entering and traveling through the overlayer if its size nears or exceeds that of nanoscopic pores or free volume elements within the overlayer. ${ }^{80-83}$ Previous characterization measurements of $\mathrm{SiO}_{x}$ overlayers made by the identical UV-ozone process used in this study have shown that they are amorphous, hydrophilic, and do not have welldefined pores spanning the thickness of the overlayer. ${ }^{56,84}$ Thus, the ions likely travel through free volume elements in $\mathrm{SiO}_{x}$ where size exclusion may occur. Despite having a smaller bare ion radius, $\mathrm{Cl}^{-}$has a hydrated radius that is very similar to that of $\mathrm{Br}^{-}$because $\mathrm{Cl}^{-}$has a higher charge density in its electron shell, creating a stronger electric field around the ion to coordinate water molecules. ${ }^{85}$ Based on the nearly identical hydrated radii, it is unlikely that steric effects involving the hydrated ions can fully account for the 2-order-of-magnitude difference between $P_{\mathrm{Br}}{ }^{-}$and $P_{\mathrm{Cl}^{-}}$. This is supported by previous studies investigating the selective transport of hydrated ions through membranes based on a size exclusion mechanism, which found that ions differing in hydrated radii by $<0.1 \AA$ typically exhibited less than a 2 -fold difference in permeability values. ${ }^{86,87}$ If the ions instead travel through the overlayer in a fully dehydrated state, a steric size exclusion mechanism is also unlikely because $\mathrm{Br}^{-}$has a larger bare ion radius than $\mathrm{Cl}^{-},{ }^{77}$ yet has a higher permeability in $\mathrm{SiO}_{x}$.

Differences in electrostatic interactions between the solute and overlayer offer another possible explanation for the origin of $P_{\mathrm{Br}}{ }^{-}>P_{\mathrm{Cl}^{-}}$. As ions partition into the overlayer, fixed charges within the overlayer can repel or attract solutes to varying degrees, giving rise to differences in species permeabilities. ${ }^{80,88,89}$ In the transport of $\mathrm{Cl}^{-}$and $\mathrm{Br}^{-}$across a membrane with sub-nanometer pores and negative fixed charges, Epsztein et al. have found that $\mathrm{Cl}^{-}$is repelled more strongly by the membrane's charges compared to $\mathrm{Br}^{-}$due to the chloride's smaller bare ion radius and therefore higher charge density. ${ }^{90}$ If the $\mathrm{SiO}_{x}$ overlayer contains negative fixed charges, these findings suggest that electrostatic repulsion would hinder the transport of $\mathrm{Cl}^{-}$more strongly than that of $\mathrm{Br}^{-}$, which is consistent with our result of $P_{\mathrm{Br}^{-}}>P_{\mathrm{Cl}^{-}}$. While $\mathrm{SiO}_{x}$ could contain negatively charged deprotonated silanol groups ( $\mathrm{Si}-$ $\mathrm{O}^{-}$), these groups would likely be protonated and neutrally or positively charged at our acidic electrolyte $\mathrm{pH}$ of 0.8 , which is below the point of zero charge for silica that typically lies between 1 and 3..$^{91,92}$ In their study, Epsztein et al. reported that below the point of zero charge, the positively charged membrane electrostatically repels the counterions of $\mathrm{Cl}^{-}$and $\mathrm{Br}^{-}$, which in turn slows the transport of $\mathrm{Cl}^{-}$and $\mathrm{Br}^{-}$to maintain electroneutrality. ${ }^{90}$ In our study at extremely low $\mathrm{pH}$, the counterion for $\mathrm{Cl}^{-}$and $\mathrm{Br}^{-}$is likely $\mathrm{H}^{+}$, which permeates through $\mathrm{SiO}_{x}$ in acidic conditions at a much faster rate than these anions, ${ }^{56}$ and would not be expected to limit their transport. Thus, a purely electrostatic mechanism is unlikely to be the reason for the difference between our observed $\mathrm{Cl}^{-}$and $\mathrm{Br}^{-}$permeabilities.

A third possible explanation for the vastly different permeabilities of $\mathrm{Cl}^{-}$and $\mathrm{Br}^{-}$is that these ions must shed all or part of their hydration sphere to enter the $\mathrm{SiO}_{x}$ matrix and that the activation energies associated with dehydration are different. If the average dimension of the free volume elements in an overlayer or membrane is smaller than the size of the ion's hydration sphere, the hydration sphere must usually be removed or rearranged to allow the ion to partition into the membrane. ${ }^{93,94}$ During dehydration, the rearrangement of the bonds between water molecules and the ion presents an energy barrier to transport. ${ }^{95}$

Whether or not it is a rate-limiting transport barrier, partial dehydration likely does occur during the transport of $\mathrm{Cl}^{-}$and $\mathrm{Br}^{-}$through $\mathrm{SiO}_{x}$. Partial dehydration is often a prerequisite for achieving selective transport between two different ions in membranes because ion dehydration exposes the unique properties of each ion for the solute-medium interactions that give rise to selective transport. ${ }^{95,96}$ Further, the polar bonds in $\mathrm{SiO}_{x}$ would likely form favorable interactions with the ions to displace ion-water interactions, promoting dehydration. ${ }^{86,97}$ Saliently, partial dehydration has been found to be a key underlying reason for selective transport across a range of membrane materials. ${ }^{83,94,98-104}$

Recent characterization measurements reported by our group for $\mathrm{SiO}_{x}$ overlayers fabricated in an identical manner to those studied here provide further support that $\mathrm{Br}^{-}$and $\mathrm{Cl}^{-}$ likely undergo partial dehydration to enter and diffuse through $\mathrm{SiO}_{x}$. Based on ellipsometric porosimetry measurements carried out with toluene, Labrador et al. concluded that most of the free volume elements within $\mathrm{SiO}_{x}$ overlayers must have a diameter smaller than the kinetic diameter of toluene, $5.8 \AA^{53}$ More recently, Beatty et al. used a combination of ellipsometry and XPS characterization to estimate the average nearestneighbor $\mathrm{Si}-\mathrm{Si}$ distances within $120 \mathrm{~min}$ cured $4.8 \mathrm{~nm} \mathrm{SiO}{ }_{x}$ overlayers to be $\approx 4.6 \AA^{56}$ The hydrated diameters of $\mathrm{Cl}^{-}$and $\mathrm{Br}^{-}$are larger by comparison at $\approx 6.5 \AA \AA^{78,105}$ suggesting that the full hydration shells would not fit within the $\mathrm{SiO}_{x}$ free volume elements and the ions would have to at least partially dehydrate to pass through.

If partial dehydration were a rate-limiting mechanism, $\mathrm{Br}^{-}$ would be expected to have a lower barrier to transport than $\mathrm{Cl}^{-}$because $\mathrm{Br}^{-}$has a larger electron shell radius and therefore a lower dehydration energy than $\mathrm{Cl}^{-79}$. This expectation is consistent with our observation that $P_{\mathrm{Br}}{ }^{-}$is greater than $P_{\mathrm{Cl}}^{-}$, warranting further consideration of a partial dehydration ratelimiting mechanism.

Mathematical models based on membrane transport theory can provide a more quantitative assessment of the differences in permeabilities that would result from a partial dehydration mechanism. In particular, an Arrhenius expression has been shown to be well suited for modeling species permeabilities through membrane materials with sub-nanometer pores or free 
volume elements where partial dehydration limits transport ${ }^{95}$ (eq 6)

$$
P_{i}=A^{\prime} \exp \left(-\frac{E_{\mathrm{a}}}{R T}\right)
$$

where $P_{i}$ is the permeability of species $i, A^{\prime}$ is a pre-exponential frequency factor, $E_{\mathrm{a}}$ is the energy barrier for the rate-limiting transport step, $R$ is the ideal gas constant, and $T$ is the absolute temperature. In cases where partial dehydration is the transport-limiting step, $E_{\mathrm{a}}$ would correlate strongly with the dehydration energy of the ion. ${ }^{98}$ Due to the exponential dependence of permeability on $E_{\mathrm{a}}$ in eq 6, a small difference in dehydration energy between $\mathrm{Cl}^{-}$and $\mathrm{Br}^{-}$could potentially lead to the observed 2-order-of-magnitude difference between the anions' permeabilities, in contrast with the more minor effect of hydrated ion radius on permeability. For example, if one assumes that two species have identical pre-exponential factors of $A^{\prime}=2 \times 10^{-7} \mathrm{~cm}^{2} \mathrm{~s}^{-1}$, similar to $A^{\prime}$ values derived from the literature, ${ }^{90}$ our observed $P_{\mathrm{Cl}^{-}}$and $P_{\mathrm{Br}^{-}}$would correspond to $E_{\mathrm{a}}$ values of 31.8 and $23.7 \mathrm{~kJ} \mathrm{~mol}^{-1}$, respectively, using eq 6 (Section XII, Supporting Information). For context, the enthalpy of hydration for $\mathrm{Cl}^{-}$and $\mathrm{Br}^{-}$, which is opposite in sign to the $E_{\mathrm{a}}$ theoretically required to fully dehydrate the ion, is -367 and $-336 \mathrm{~kJ} \mathrm{~mol}^{-1}$, respectively. ${ }^{106}$ Since the energy barrier for partial dehydration is expected to be a fraction of the full dehydration energy, ${ }^{93,107}$ our calculated $E_{\mathrm{a}}$ values are reasonable for a partial dehydration rate-limiting step.

Because the partial dehydration explanation aligns well with our preliminary empirical analysis, we posit that partial dehydration is a rate-limiting step for $\mathrm{Cl}^{-}$transport through the $\mathrm{SiO}_{x}$ overlayers investigated in this work. Furthermore, partial dehydration could help explain the overlayer's selectivity for the OER over the CER since $\mathrm{H}_{2} \mathrm{O}$, the reactant for the OER, is the solvent within the aqueous electrolyte and is expected to have a much smaller activation barrier for crossing from the bulk electrolyte into the hydrophilic $\mathrm{SiO}_{x}$ overlayer. The most common water cluster sizes at $\mathrm{pH} 1$, $\left(\mathrm{H}_{2} \mathrm{O}\right)_{1-6}{ }^{108}$ have full dissociation energies of less than $57 \mathrm{~kJ}$ $\mathrm{mol}^{-1}$, 109 suggesting that water's partial self-dehydration energy is far smaller than the partial dehydration energy of $\mathrm{Cl}^{-}$and $\mathrm{Br}^{-}$.

While the comparison of $\mathrm{Cl}^{-}$and $\mathrm{Br}^{-}$permeabilities appears to be consistent with partial ion dehydration playing a key role in determining relative transport rates, further work is needed to prove this hypothesis and address other unanswered questions related to transport mechanisms through ultrathin oxide coatings on electrodes. For example, the role of electromigration on species transport in ultrathin oxide coatings is generally unknown, as is the importance of stabilizing interactions between ions and electrode coatings. ${ }^{96,110}$ Though the difference between $P_{\mathrm{Cl}^{-}}$and $P_{\mathrm{Br}^{-}}$can be described by realistic differences in partial dehydration $E_{\mathrm{a}}$ values computed based on an Arrhenius expression, differences in the pre-exponential factor in this relation could also account for the permeability differences. In distinct membrane transport cases, the $A^{\prime}$ value for $\mathrm{Cl}^{-}$has been found to be orders of magnitude larger, orders smaller, or nearly identical to that of $\mathrm{Br}^{-} \cdot{ }^{90,98,111}$ While no rate-limiting step considered here shows indication of creating a large difference in $A^{\prime}$ for $\mathrm{SiO}_{x}$ transport, such a difference may arise through poorly understood mechanisms such as electromigration or stabilizing interactions within the overlayer. Further experiments that expand to additional redox species with varying valency, size, and polarity, combined with operando structural characterization of the overlayers and atomistic simulations, are expected to be essential to further establishing design rules for selective oxide overlayers for seawater electrolysis.

\section{CONCLUSIONS}

This study has demonstrated that a catalytically inert $\mathrm{SiO}_{x}$ overlayer deposited on a planar Pt electrocatalyst can leverage selective transport properties of the overlayer to greatly suppress the CER while still permitting the desired OER to take place during electrolysis in a simulated acidic seawater environment. The ability of $\mathrm{SiO}_{x}$ overlayers to selectively block the CER is demonstrated in both acidic and $\mathrm{pH}$-neutral environments that thermodynamically favor the CER, even at the high $0.6 \mathrm{M}$ chloride concentration typical of seawater, at large CER overpotentials approaching $600 \mathrm{mV}$, and on a $\mathrm{Pt}$ electrocatalyst that is not particularly active for the OER. Based on mass transfer-limiting current densities, the $\mathrm{SiO}_{x}$ overlayers are characterized by a $\mathrm{Cl}^{-}$permeability that is 3 orders of magnitude lower than that of a conventional reverse osmosis membrane. The chloride rejection of $\mathrm{SiO}_{x}$ overlayers could be further improved through optimization of the composition and structure of these overlayers, including possibly by incorporating anionic fixed charges into the overlayer to electrostatically repel $\mathrm{Cl}^{-}$.

The overlayers also show robust stability in $12 \mathrm{~h} \mathrm{CA}$ measurements at $1.55 \mathrm{~V}$ vs RHE, although some delamination becomes evident after a $12 \mathrm{~h} \mathrm{CA}$ at a more positive potential of $1.90 \mathrm{~V}$ vs RHE. These instability issues are believed to be related to the formation of a $\mathrm{PtO}_{x}$ interlayer at the $\mathrm{SiO}_{x} \mid \mathrm{Pt}$ buried interface on model thin film electrodes, suggesting that it should be possible to overcome this issue with alternative electrodes with optimized structure and composition that improves anchoring or avoids the formation of undesirable $\mathrm{PtO}_{x}$ interlayers. If the catalytic and adhesion properties of the buried interface can be improved while further enhancing the $\mathrm{H}_{2} \mathrm{O} / \mathrm{Cl}^{-}$transport selectivity of overlayers, $\mathrm{SiO}_{x}$-encapsulated electrocatalysts will offer an attractive means of achieving OER-selective seawater electrolysis without the added challenges of engineering electrolyte $\mathrm{pH}$ and mitigating chlorine corrosion.

\section{EXPERIMENTAL SECTION}

4.1. Electrode Fabrication. Monocrystalline degeneratively doped $\mathrm{Si}(100)$ wafers $\left(\mathrm{p}^{+} \mathrm{Si}<0.005 \Omega \mathrm{cm}, 500-550 \mu \mathrm{m}\right.$ thick, WRS Materials) were used as conductive support substrates. To create the electrodes used in this study, thin films of $\mathrm{Pt}$ were deposited onto the $\mathrm{p}^{+} \mathrm{Si}$ support with an adhesion layer of $\mathrm{Ti}$ in between the $\mathrm{p}^{+} \mathrm{Si}$ and $\mathrm{Pt}$. More specifically, thin films of $2 \mathrm{~nm}$ thick Ti (99.99\%) and $3 \mathrm{~nm}$ thick $\mathrm{Pt}$ (99.99\%) were sequentially deposited using electronbeam evaporation at $0.2 \mathrm{~A} \mathrm{~s}^{-1}$ without breaking vacuum and without substrate heating. Electron-beam evaporation was performed with a base pressure of $1.0 \times 10^{-7}$ Torr in an Angstrom EvoVac evaporator system, with quartz crystal thickness monitors used to monitor film thicknesses. The Ptl Tilp ${ }^{+} \mathrm{Si}$ wafer was cleaved into $1.5 \times 2 \mathrm{~cm}^{2}$ pieces and then rinsed successively in acetone, methanol, isopropyl alcohol, and deionized water. Trimethylsiloxy-terminated poly(dimethylsiloxane) (PDMS) was spin-coated onto the Pt|Til $\mathrm{p}^{+} \mathrm{Si}$ substrates at a speed of $4500 \mathrm{rpm}$ for $2 \mathrm{~min}$ and $30 \mathrm{~s}$ using 
four drops of PDMS/toluene solution that was deposited before spinning was initiated. PDMS in toluene concentrations of $1.2,2.1,3.0,4.5$, and $5.3 \mathrm{mg} \mathrm{mL}^{-1}$ were used to achieve $\mathrm{SiO}_{x}$ overlayer thicknesses of $1.2,2.9,4.8,5.4$, and $8.7 \mathrm{~nm}$, respectively. The electrodes were then dried in an oven at atmospheric pressure at $90{ }^{\circ} \mathrm{C}$ for $60 \mathrm{~min}$ to evaporate the solvent. Afterward, the PDMS was converted to $\mathrm{SiO}_{x}$ in a UVozone cleaning chamber for $2 \mathrm{~h}$ (UVOCS, T10X10/OES). A low-resistance electrical back-contact was made by first scratching the back of the $\mathrm{p}^{+} \mathrm{Si}$ substrate and then attaching a copper wire to the scratched area using indium solder. Finally, the electrodes were sealed in $3 \mathrm{M}$ Electroplater's Tape to protect the back-contact and create a well-defined $0.26 \mathrm{~cm}^{2}$ circular opening on the front of the electrode for electrochemical measurements.

4.2. Material Characterization. The thicknesses of the $\mathrm{SiO}_{x}$ films on the Pt|Tilp ${ }^{+} \mathrm{Si}$ substrates were measured using a Woollam alpha-SE ellipsometer and fit with a Cauchy model. Images of the electrodes were taken using a Zeiss Sigma VP Schottky thermal field emission scanning electron microscope (SEM). X-ray photoelectron spectroscopy (XPS) measurements were made with a Phi XPS system at pressures $<2$ $\times 10^{-10}$ Torr using a monochromatic Al K $\alpha$ source $(12.5 \mathrm{kV}$, $24 \mathrm{~mA}$ ), with a pass energy of $23.5 \mathrm{eV}$, a step size of $0.05 \mathrm{eV}$, and a hold time of $200 \mathrm{~ms}$. All samples were kept at $45^{\circ}$ relative to the X-ray source. $\mathrm{Si} 2 \mathrm{p}$ and $\mathrm{Pt} 4 \mathrm{f}$ spectra were recorded, and analysis of the XPS data was performed as detailed elsewhere. ${ }^{53}$ As previously reported, the as-deposited $\mathrm{Pt}$ thin films are characterized by rms roughness values $<1$ nm. ${ }^{52}$ The fabrication method yielded a continuous, smooth $\mathrm{SiO}_{x}$ film of uniform thickness, as verified by atomic force microscopy (AFM) and ellipsometry measurements in previous studies. $^{52,53}$

4.3. Electrochemical Measurements. Electrochemical measurements were performed at $25{ }^{\circ} \mathrm{C}$ in deaerated $0.5 \mathrm{M}$ potassium bisulfate $(+0.6 \mathrm{M}$ potassium chloride) $(+20 \mathrm{mM}$ potassium bromide) prepared from potassium bisulfate salt ( $\mathrm{KHSO}_{4}$, reagent grade, Sigma-Aldrich), potassium chloride salt ( $\mathrm{KCl}$, anhydrous, Sigma-Aldrich), potassium bromide salt (KBr, anhydrous, Sigma-Aldrich), and $18 \mathrm{M} \Omega$ deionized water (Millipore, Milli-Q Direct 8). Unbuffered $\mathrm{pH}$-neutral electrochemical measurements were performed in deaerated $0.1 \mathrm{M}$ potassium nitrate and $0.6 \mathrm{M}$ potassium chloride prepared from potassium nitrate salt $\left(\mathrm{KNO}_{3}\right.$, ACS reagent, Sigma-Aldrich), potassium chloride salt, and $18 \mathrm{M} \Omega$ deionized water. Additional measurements were performed in $0.5 \mathrm{M}$ sulfuric acid + 0.6 M sodium chloride prepared from concentrated sulfuric acid $\left(\mathrm{H}_{2} \mathrm{SO}_{4}\right.$, certified ACS plus, Fischer Scientific), sodium chloride salt ( $\mathrm{NaCl}$, anhydrous, Sigma-Aldrich), and $18 \mathrm{M} \Omega$ deionized water.

All electrochemical measurements were conducted with an SP-200 or SP-300 BioLogic potentiostat and carried out in a standard three-neck round-bottom glass cell with a commercial $\mathrm{Ag} \mid \mathrm{AgCl}(3 \mathrm{M} \mathrm{KCl})$ reference electrode $(\mathrm{E} 1 / 40.210 \mathrm{~V}$ vs NHE, Hach, E21M002) and a graphite rod counter electrode (Gamry). The electrolyte was stirred using a 3-inch-long magnetic stir bar at $200 \mathrm{rpm}$ throughout all measurements. Newly made samples were used for each measurement. Immediately preceding each LSV or CA measurement, the existing $\mathrm{Pt}$ oxide at the $\mathrm{Pt}$ surface of the electrode was reduced to metallic Pt using three $\mathrm{CV}$ cycles between +0.04 and +0.94 $\mathrm{V}$ vs RHE.

\section{ASSOCIATED CONTENT}

\section{Supporting Information}

The Supporting Information is available free of charge at https://pubs.acs.org/doi/10.1021/acscatal.0c04343.

Electrochemical measurements in the supporting electrolyte of raised ionic density, time evolution of $\mathrm{CV}$ for $4.8 \mathrm{~nm} \mathrm{SiO} \mathrm{Sit}_{x} \mathrm{Pt}$ in the saline electrolyte, LSV measurements for varied thickness $\mathrm{SiO}_{x}|\mathrm{Pt}, 4.8 \mathrm{~nm} \mathrm{SiO}|_{x} \mathrm{Pt} \mathrm{LSV}$ subtraction curve between the supporting and saline electrolytes, LSV measurements in neutral $\mathrm{pH}$ electrolytes, LSV measurements in the presence of $0.6 \mathrm{M} \mathrm{NaCl}$, faradic efficiencies for OER, bromine evolution measurements for $4.8 \mathrm{~nm} \mathrm{SiO}{ }_{x} \mid \mathrm{Pt}$, and methods for calculation of $P_{\mathrm{Br}^{-}}$and $E_{\mathrm{a}}(\mathrm{PDF})$

\section{AUTHOR INFORMATION}

\section{Corresponding Author}

Daniel V. Esposito - Department of Chemical Engineering, Columbia Electrochemical Engineering Center, Lenfest Center for Sustainable Energy, Columbia University in the City of New York, New York 10027, United States; ㅇo이.org/ 0000-0002-0550-801X; Email: de2300@columbia.edu

\section{Authors}

Amar A. Bhardwaj - Department of Chemical Engineering, Columbia Electrochemical Engineering Center, Lenfest Center for Sustainable Energy, Columbia University in the City of New York, New York 10027, United States; (이이.org/ 0000-0002-1082-7306

Johannes G. Vos - Leiden Institute of Chemistry, Leiden University, 2300 RA Leiden, The Netherlands

Marissa E. S. Beatty - Department of Chemical Engineering, Columbia Electrochemical Engineering Center, Lenfest Center for Sustainable Energy, Columbia University in the City of New York, New York 10027, United States

Amanda F. Baxter - Department of Chemical Engineering, Columbia Electrochemical Engineering Center, Lenfest Center for Sustainable Energy, Columbia University in the City of New York, New York 10027, United States

Marc T. M. Koper - Leiden Institute of Chemistry, Leiden University, 2300 RA Leiden, The Netherlands

Ngai Yin Yip - Department of Earth and Environmental Engineering, Columbia Water Center, Columbia University in the City of New York, New York 10027, United States

Complete contact information is available at:

https://pubs.acs.org/10.1021/acscatal.0c04343

\section{Notes}

The authors declare the following competing financial interest(s): D.V.E. is a co-founder of sHYp, B.V.

\section{ACKNOWLEDGMENTS}

J.G.V. and M.T.M.K. acknowledge funding support from the Netherlands Organization for Scientific Research (NWO) in the framework of the fund New Chemical Innovations, project 731.015.204 ELECTROGAS, with financial support of Akzo Nobel Chemicals/Nouryon, Shell Global Solutions, Magneto Special Anodes (an Evoqua Brand), and Elson Technologies. A.A.B. acknowledges funding support from the Deresiewicz Research Fellowship, the Columbia University Materials Research Science and Engineering Center REU program, the Columbia Engineering Dean's Office Research Fellowship, and 
the American Membrane Technology Association Fellowship. M.E.S.B. and D.V.E. acknowledge funding from the National Science Foundation (NSF) under Grant Number (CBET1752340). D.V.E. and A.F.B. acknowledge funding support from the Qatar National Research Fund under its National Priorities Research Program award number NPRP12S-0131190024 and co-funding from the Qatar Shell Research and Technology Center (QSRTC). Any opinions, findings, and conclusions or recommendations expressed in this material are those of the author(s) and do not necessarily reflect the views of the National Science Foundation.

\section{REFERENCES}

(1) Decker, G. L.; Gouse, W. S.; Gregory, D. P.; Hirsch, R. L.; Hoffman, K. C.; Hoos, I. R.; Johnson, J. E.; Longwell, J. P.; Siri, W. E.; Sliepcevich, C. M.; Smelt, R. Hydrogen as a Fuel; National Academies Press, 1979.

(2) Drab, D. M.; Willauer, H. D.; Olsen, M. T.; Ananth, R.; Mushrush, G. W.; Baldwin, J. W.; Hardy, D. R.; Williams, F. W. Hydrocarbon Synthesis from Carbon Dioxide and Hydrogen: A TwoStep Process. Energy Fuels 2013, 27, 6348-6354.

(3) Fukuzumi, S.; Lee, Y.-M.; Nam, W. Fuel Production from Seawater and Fuel Cells Using Seawater. ChemSusChem 2017, 10, 4264-4276.

(4) Jain, I. P. Hydrogen the Fuel for 21st Century. Int. J. Hydrogen Energy 2009, 34, 7368-7378.

(5) Dresp, S.; Dionigi, F.; Klingenhof, M.; Strasser, P. Direct Electrolytic Splitting of Seawater: Opportunities and Challenges. ACS Energy Lett. 2019, 4, 933-942.

(6) Urban, J. J. Emerging Scientific and Engineering Opportunities within the Water-Energy Nexus. Joule 2017, 1, 665-688.

(7) Dionigi, F.; Reier, T.; Pawolek, Z.; Gliech, M.; Strasser, P. Design Criteria, Operating Conditions, and Nickel-Iron Hydroxide Catalyst Materials for Selective Seawater Electrolysis. ChemSusChem 2016, 9, 962-972.

(8) Ahuja, K.; Mamtani, K. Hypochlorite Bleaches Market Size by Product (Sodium Hypochlorite, Calcium Hypochlorite, Potassium Hypochlorite, Lithium Hypochlorite), by Application (Water Treatment, Textiles, Residential Pool Treatment, Laundry Bleaching, Disinfectants, Paper \& Pulp), Industry Outlook Report, Regional Analysis, Application Potential, Price Trends, Competitive Market Share \& Forecast, 20192025; Global Market Insights, 2019.

(9) Hydrogen Generation Market Size, Share \& Trends Analysis Report by Application (Coal Gasification, Steam Methane Reforming), by Systems (Merchant, Captive), by Technology, and Segment Forecasts, 2020-2027; Grand View Research, 2020.

(10) Chlorine Market by Production Method, by Application, by Industry Verticals (Pharmaceutical, Water Treatment, Paper \& Pulp, Chemical, Plastic, and Others), and Segment Forecasts, 2016-2027; Reports and Data, 2019.

(11) Koper, M. T. M. Thermodynamic Theory of Multi-Electron Transfer Reactions: Implications for Electrocatalysis. J. Electroanal. Chem. 2011, 660, 254-260.

(12) Fujimura, K.; Izumiya, K.; Kawashima, A.; Akiyama, E.; Habazaki, H.; Kumagai, N.; Hashimoto, K. Anodically Deposited Manganese-Molybdenum Oxide Anodes with High Selectivity for Evolving Oxygen in Electrolysis of Seawater. J. Appl. Electrochem. 1999, 29, 765-771.

(13) Kuang, Y.; Kenney, M. J.; Meng, Y.; Hung, W. H.; Liu, Y.; Huang, J. E.; Prasanna, R.; Li, P.; Li, Y.; Wang, L.; Lin, M. C.; McGehee, M. D.; Sun, X.; Dai, H. Solar-Driven, Highly Sustained Splitting of Seawater into Hydrogen and Oxygen Fuels. Proc. Natl. Acad. Sci. U.S.A. 2019, 116, 6624-6629.

(14) Amikam, G.; Nativ, P.; Gendel, Y. Chlorine-Free Alkaline Seawater Electrolysis for Hydrogen Production. Int. J. Hydrogen Energy 2018, 43, 6504-6514.

(15) El-Moneim, A. A. Mn-Mo-W-Oxide Anodes for Oxygen Evolution During Seawater Electrolysis for Hydrogen Production:
Effect of Repeated Anodic Deposition. Int. J. Hydrogen Energy 2011, $36,13398-13406$.

(16) Huang, W. H.; Lin, C. Y. Iron Phosphate Modified Calcium Iron Oxide as an Efficient and Robust Catalyst in Electrocatalyzing Oxygen Evolution from Seawater. Faraday Discuss. 2019, 215, 205215.

(17) Yu, L.; Zhu, Q.; Song, S.; McElhenny, B.; Wang, D.; Wu, C.; Qin, Z.; Bao, J.; Yu, Y.; Chen, S.; Ren, Z. Non-Noble Metal-Nitride Based Electrocatalysts for High-Performance Alkaline Seawater Electrolysis. Nat. Commun. 2019, 10, No. 5106.

(18) Song, H. J.; Yoon, H.; Ju, B.; Lee, D.-Y.; Kim, D.-W. Electrocatalytic Selective Oxygen Evolution of Carbon-Coated $\mathrm{Na} 2 \mathrm{Co} 1-\mathrm{xFexP2O} 7$ Nanoparticles for Alkaline Seawater Electrolysis. ACS Catal. 2020, 10, 702-709.

(19) Dresp, S.; Ngo Thanh, T.; Klingenhof, M.; Brückner, S.; Hauke, P.; Strasser, P. Efficient Direct Seawater Electrolysers Using Selective Alkaline NiFe-LDH As OER Catalyst in Asymmetric Electrolyte Feeds. Energy Environ. Sci. 2020, 1725.

(20) Dresp, S.; Dionigi, F.; Loos, S.; Ferreira de Araujo, J.; Spöri, C.; Gliech, M.; Dau, H.; Strasser, P. Direct Electrolytic Splitting of Seawater: Activity, Selectivity, Degradation, and Recovery Studied from the Molecular Catalyst Structure to the Electrolyzer Cell Level. Adv. Energy Mater. 2018, 8, No. 1800338.

(21) Yu, L.; Wu, L.; McElhenny, B.; Song, S.; Luo, D.; Zhang, F.; Yu, Y.; Chen, S.; Ren, Z. Ultrafast Room-Temperature Synthesis of Porous S-Doped $\mathrm{Ni} / \mathrm{Fe}$ (Oxy)Hydroxide Electrodes for Oxygen Evolution Catalysis in Seawater Splitting. Energy Environ. Sci. 2020, 13, 3439-3446.

(22) Đukić, A.; Firak, M. Hydrogen Production Using Alkaline Electrolyzer and Photovoltaic (PV) Module. Int. J. Hydrogen Energy 2011, 36, 7799-7806.

(23) Meier, K. Hydrogen Production with Sea Water Electrolysis Using Norwegian Offshore Wind Energy Potentials. Int. J. Energy Environ. Eng. 2014, 5, No. 104.

(24) d'Amore-Domenech, R.; Leo, T. J. Sustainable Hydrogen Production from Offshore Marine Renewable Farms: TechnoEnergetic Insight on Seawater Electrolysis Technologies. ACS Sustainable Chem. Eng. 2019, 7, 8006-8022.

(25) Hessami, S.; Tobias, C. W. In-Situ Measurement of Interfacial pH Using a Rotating Ring-Disk Electrode. AIChE J. 1993, 39, 149162.

(26) Snizhko, L. O.; Yerokhin, A. L.; Gurevina, N. L.; Patalakha, V. A.; Matthews, A. Excessive Oxygen Evolution During Plasma Electrolytic Oxidation of Aluminium. Thin Solid Films 2007, 516, 460-464.

(27) Tong, W.; Forster, M.; Dionigi, F.; Dresp, S.; Sadeghi Erami, R.; Strasser, P.; Cowan, A. J.; Farràs, P. Electrolysis of Low-Grade and Saline Surface Water. Nat. Energy 2020, 5, 367-377.

(28) Kadier, A.; Simayi, Y.; Abdeshahian, P.; Azman, N. F.; Chandrasekhar, K.; Kalil, M. S. A. Comprehensive Review of Microbial Electrolysis Cells (MEC) Reactor Designs and Configurations for Sustainable Hydrogen Gas Production. Alexandria Eng. J. 2016, 55, 427-443.

(29) Jwa, E.; Yun, Y.-M.; Kim, H.; Jeong, N.; Hwang, K. S.; Yang, S.; Nam, J.-Y. Energy-Efficient Seawater Softening and Power Generation Using a Microbial Electrolysis Cell-Reverse Electrodialysis Hybrid System. Chem. Eng. J. 2020, 391, No. 123480.

(30) McCrory, C. C.; Jung, S.; Ferrer, I. M.; Chatman, S. M.; Peters, J. C.; Jaramillo, T. F. Benchmarking Hydrogen Evolving Reaction and Oxygen Evolving Reaction Electrocatalysts for Solar Water Splitting Devices. J. Am. Chem. Soc. 2015, 137, 4347-4357.

(31) Petrykin, V.; Macounova, K.; Shlyakhtin, O. A.; Krtil, P. Tailoring the Selectivity for Electrocatalytic Oxygen Evolution on Ruthenium Oxides by Zinc Substitution. Angew. Chem., Int. Ed. 2010, 49, 4813-4815.

(32) Kato, Z.; Bhattarai, J.; Kumagai, N.; Izumiya, K.; Hashimoto, K. Durability Enhancement and Degradation of Oxygen Evolution Anodes in Seawater Electrolysis for Hydrogen Production. Appl. Surf. Sci. 2011, 257, 8230-8236. 
(33) Kato, Z.; Sato, M.; Sasaki, Y.; Izumiya, K.; Kumagai, N.; Hashimoto, K. Electrochemical Characterization of Degradation of Oxygen Evolution Anode for Seawater Electrolysis. Electrochim. Acta 2014, 116, 152-157.

(34) El-Moneim, A. A.; Kumagai, N.; Asami, K.; Hashimoto, K. Nanocrystalline Manganese-Molybdenum-Tungsten Oxide Anodes for Oxygen Evolution in Acidic Seawater Electrolysis. Mater. Trans. 2005, 46, 309-316.

(35) Dinh, C.-T.; Jain, A.; de Arquer, F. P. G.; De Luna, P.; Li, J.; Wang, N.; Zheng, X.; Cai, J.; Gregory, B. Z.; Voznyy, O.; Zhang, B.; Liu, M.; Sinton, D.; Crumlin, E. J.; Sargent, E. H. Multi-Site Electrocatalysts for Hydrogen Evolution in Neutral Media by Destabilization of Water Molecules. Nat. Energy 2019, 4, 107-114.

(36) Esswein, A. J.; Surendranath, Y.; Reece, S. Y.; Nocera, D. G. Highly Active Cobalt Phosphate and Borate Based Oxygen Evolving Catalysts Operating in Neutral and Natural Waters. Energy Environ. Sci. 2011, 4, 499-504.

(37) Hsu, S. H.; Miao, J.; Zhang, L.; Gao, J.; Wang, H.; Tao, H.; Hung, S. F.; Vasileff, A.; Qiao, S. Z.; Liu, B. An Earth-Abundant Catalyst-Based Seawater Photoelectrolysis System with $17.9 \%$ Solarto-Hydrogen Efficiency. Adv. Mater. 2018, 30, No. e1707261.

(38) Surendranath, Y.; Dinca, M.; Nocera, D. G. ElectrolyteDependent Electrosynthesis and Activity of Cobalt-Based Water Oxidation Catalysts. J. Am. Chem. Soc. 2009, 131, 2615-2620.

(39) Carneiro-Neto, E. B.; Lopes, M. C.; Pereira, E. C. Simulation of Interfacial $\mathrm{pH}$ Changes During Hydrogen Evolution Reaction. J. Electroanal. Chem. 2016, 765, 92-99.

(40) Sharma, S. K. Green Corrosion Chemistry and Engineering: Opportunities and Challenges; Wiley-VCH Verlag GmbH \& Co. KGaA: Weinheim, Germany, 2011.

(41) Bau, J. A.; Takanabe, K. Ultrathin Microporous $\mathrm{SiO} 2$ Membranes Photodeposited on Hydrogen Evolving Catalysts Enabling Overall Water Splitting. ACS Catal. 2017, 7, 7931-7940.

(42) Qureshi, M.; Shinagawa, T.; Tsiapis, N.; Takanabe, K. Exclusive Hydrogen Generation by Electrocatalysts Coated with an Amorphous Chromium-Based Layer Achieving Efficient Overall Water Splitting. ACS Sustainable Chem. Eng. 2017, 5, 8079-8088.

(43) Vos, J. G.; Wezendonk, T. A.; Jeremiasse, A. W.; Koper, M. T. M. $\mathrm{MnOx} / \mathrm{IrOx}$ as Selective Oxygen Evolution Electrocatalyst in Acidic Chloride Solution. J. Am. Chem. Soc. 2018, 140, 10270-10281.

(44) Balaji, R.; Kannan, B. S.; Lakshmi, J.; Senthil, N.; Vasudevan, S.; Sozhan, G.; Shukla, A. K.; Ravichandran, S. An Alternative Approach to Selective Sea Water Oxidation for Hydrogen Production. Electrochem. Commun. 2009, 11, 1700-1702.

(45) Venkatkarthick, R.; Elamathi, S.; Sangeetha, D.; Balaji, R.; Suresh Kannan, B.; Vasudevan, S.; Jonas Davidson, D.; Sozhan, G.; Ravichandran, S. Studies on Polymer Modified Metal Oxide Anode for Oxygen Evolution Reaction in Saline Water. J. Electroanal. Chem. 2013, 697, 1-4.

(46) Garcia-Esparza, A. T.; Shinagawa, T.; Ould-Chikh, S.; Qureshi, M.; Peng, X.; Wei, N.; Anjum, D. H.; Clo, A.; Weng, T. C.; Nordlund, D.; Sokaras, D.; Kubota, J.; Domen, K.; Takanabe, K. An OxygenInsensitive Hydrogen Evolution Catalyst Coated by a MolybdenumBased Layer for Overall Water Splitting. Angew. Chem., Int. Ed. 2017, $56,5780-5784$

(47) Obata, K.; Takanabe, K. A Permselective CeOx Coating To Improve the Stability of Oxygen Evolution Electrocatalysts. Angew. Chem., Int. Ed. 2018, 57, 1616-1620.

(48) Vos, J. G.; Liu, Z.; Speck, F. D.; Perini, N.; Fu, W.; Cherevko, S.; Koper, M. T. M. Selectivity Trends Between Oxygen Evolution and Chlorine Evolution on Iridium-Based Double Perovskites in Acidic Media. ACS Catal. 2019, 9, 8561-8574.

(49) Huynh, M.; Bediako, D. K.; Nocera, D. G. A Functionally Stable Manganese Oxide Oxygen Evolution Catalyst in Acid. J. Am. Chem. Soc. 2014, 136, 6002-6010.

(50) Li, A.; Ooka, H.; Bonnet, N.; Hayashi, T.; Sun, Y.; Jiang, Q.; Li, C.; Han, H.; Nakamura, R. Stable Potential Windows for Long-Term Electrocatalysis by Manganese Oxides Under Acidic Conditions. Angew. Chem., Int. Ed. 2019, 58, 5054-5058.
(51) Ouyang, M.; Muisener, R. J.; Boulares, A.; Koberstein, J. T. UV-Ozone Induced Growth of a SiOx Surface Layer on a CrossLinked Polysiloxane Film: Characterization and Gas Separation Properties. J. Membr. Sci. 2000, 177, 177-187.

(52) Beatty, M. E. S.; Chen, H.; Labrador, N. Y.; Lee, B. J.; Esposito, D. V. Structure-Property Relationships Describing the Buried Interface Between Silicon Oxide Overlayers and Electrocatalytic Platinum Thin Films. J. Mater. Chem. A 2018, 6, 22287-22300.

(53) Labrador, N. Y.; Songcuan, E. L.; De Silva, C.; Chen, H.; Kurdziel, S. J.; Ramachandran, R. K.; Detavernier, C.; Esposito, D. V. Hydrogen Evolution at the Buried Interface between Pt Thin Films and Silicon Oxide Nanomembranes. ACS Catal. 2018, 8, 1767-1778.

(54) Robinson, J. E.; Labrador, N. Y.; Chen, H.; Sartor, B. E.; Esposito, D. V. Silicon Oxide-Encapsulated Platinum Thin Films as Highly Active Electrocatalysts for Carbon Monoxide and Methanol Oxidation. ACS Catal. 2018, 8, 11423-11434.

(55) Pourbaix, M. Atlas of Electrochemical Equilibria in Aqueous Solutions; National Association of Corrosion Engineers: Houston, Texas, 1974.

(56) Beatty, M. E. S.; Gillette, E. I.; Haley, A. T.; Esposito, D. V. Controlling the Relative Fluxes of Protons and Oxygen to Electrocatalytic Buried Interfaces with Tunable Silicon Oxide Overlayers. ACS Appl. Energy Mater. 2020, 3 (12), 12338-12350.

(57) Yuan, G.; Agiral, A.; Pellet, N.; Kim, W.; Frei, H. Inorganic Core-Shell Assemblies for Closing the Artificial Photosynthetic Cycle. Faraday Discuss. 2014, 176, 233-249.

(58) Conway, B. E. Electrochemical Oxide Film Formation at Noble Metals as a Surface-Chemical Process. Prog. Surf. Sci. 1995, 49, 331452.

(59) Conway, B. E.; Mozota, J., Chloride-ion Effects on the Reversible and Irreversible Surface Oxidation Processes at $\mathrm{Pt}$ Electrodes, and on the Growth of Monolayer Oxide Films at Pt. J. Chem. Soc., Faraday Trans. 1 1982, 78, DOI: 10.1039/f19827801717.

(60) Kolics, A.; Wieckowski, A. Adsorption of Bisulfate and Sulfate Anions on a Pt(111) Electrode. J. Phys. Chem. B 2001, 105, 25882595.

(61) Harvey, H. W. The Chemistry and Fertility of Sea Waters. J. Mar. Biol. Assoc. U.K. 1956, 35, 289.

(62) Novak, D. M.; Conway, B. E. Competitive Adsorption and State of Charge of Halide Ions in Monolayer Oxide Film Growth Processes at Pt Anodes. J. Chem. Soc., Faraday Trans. 1 1981, 77, 2341.

(63) Pavlišič, A.; Jovanovic, P.; Selih, V. S.; Sala, M.; Hodnik, N.; Hocevar, S.; Gaberscek, M. The Influence of Chloride Impurities on $\mathrm{Pt} / \mathrm{C}$ Fuel Cell Catalyst Corrosion. Chem. Commun. 2014, 50, 37323734.

(64) Real, S. G.; Barbosa, M. R.; Vilche, J. R.; Arvia, A. J. Influence of Chloride Concentration on the Active Dissolution and Passivation of Nickel Electrodes in Acid Sulfate Solutions. J. Electrochem. Soc. 1990, 137, 1696.

(65) Tsuru, T. Anodic Dissolution Mechanisms of Metals and Alloys. Mater. Sci. Eng., A 1991, 146, 1-14.

(66) Jung, H.; Alfantazi, A. Corrosion Properties of Electrodeposited Cobalt in Sulfate Solutions Containing Chloride Ions. Electrochim. Acta 2010, 55, 865-869.

(67) Moreno-Hernandez, I. A.; Brunschwig, B. S.; Lewis, N. S. Crystalline Nickel, Cobalt, and Manganese Antimonates as Electrocatalysts for the Chlorine Evolution Reaction. Energy Environ. Sci. 2019, 12, 1241-1248.

(68) Lobo, V. M. M.; Ribeiro, A. C. F.; Verissimo, L. M. P. Diffusion Coefficients in Aqueous Solutions of Potassium Chloride at High and Low Concentrations. J. Mol. Liq. 1998, 78, 139-149.

(69) Ohya, H.; Semenova, S.; Mizoguchi, K.; Ogihara, J.; Fukaya, S.; Suzuki, Y.; Aihara, M.; Negishi, Y. Distribution and Diffusion Coefficients of $\mathrm{NaCl}$ in Polyamide (Nylon-6,6 and Polyxylyleneadipamide) Membranes. J. Appl. Polym. Sci. 2002, 84, 2605-2612.

(70) Ren, H.; German, S. R.; Edwards, M. A.; Chen, Q.; White, H. S. Electrochemical Generation of Individual $\mathrm{O} 2$ Nanobubbles via $\mathrm{H} 2 \mathrm{O} 2$ Oxidation. J. Phys. Chem. Lett. 2017, 8, 2450-2454. 
(71) Gottesfeld, S.; Maia, G.; Floriano, J. B.; Tremilioso-Filho, G.; Ticianelli, E. A.; Gonzalez, E. R. Study of Thick Anodic Oxide Films on Pt by Spectroscopic Ellipsometry. J. Electrochem. Soc. 1991, 138, $3219-3224$.

(72) Miles, M. H.; Klaus, E. A.; Gunn, B. P.; Locker, J. R.; Serafin, W. E.; Srinivasan, S. The Oxygen Evolution Reaction on Platinum, Iridium, Ruthenium and Their Alloys at $80{ }^{\circ} \mathrm{C}$ in Acid Solutions. Electrochim. Acta 1978, 23, 521-526.

(73) Roscoe, S. G.; Conway, B. E. State Of Surface Oxide Films at Pt Anodes and "Volcano" Behaviour in Electrocatalysis for Anodic $\mathrm{Cl}_{2}$ Evolution. J. Electroanal. Chem. Interfacial Electrochem. 1987, 224, 163-188.

(74) Takenaka, S.; Miyamoto, H.; Utsunomiya, Y.; Matsune, H.; Kishida, M. Catalytic Activity of Highly Durable Pt/CNT Catalysts Covered with Hydrophobic Silica Layers for the Oxygen Reduction Reaction in PEFCs. J. Phys. Chem. C 2014, 118, 774-783.

(75) Takenaka, S.; Miyazaki, T.; Matsune, H.; Kishida, M. Highly Active and Durable Silica-Coated Pt Cathode Catalysts for Polymer Electrolyte Fuel Cells: Control of Micropore Structures in Silica Layers. Catal. Sci. Technol. 2015, 5, 1133-1142.

(76) Jo, W. J.; Katsoukis, G.; Frei, H. Ultrathin Amorphous Silica Membrane Enhances Proton Transfer Across Solid-to-Solid Interfaces of Stacked Metal Oxide Nanolayers While Blocking Oxygen. Adv. Funct. Mater. 2020, 30, No. 1909262.

(77) Israelachvili, J. N. Interactions Involving Polar Molecules. Intermolecular and Surface Forces; Academic Press, 2011; pp 71-90.

(78) Nightingale, E. R., Jr. Phenomenological Theory of Ion Solvation: Effective Radii of Hydrated Ions. J. Phys. Chem. A 1959, 63, 1381-1387.

(79) Fawcett, R. W. Thermodynamic Parameters for the Solvation of Monatomic Ions in Water. J. Phys. Chem. B 1999, 103, 11181-11185.

(80) O’Hern, S. C.; Boutilier, M. S.; Idrobo, J. C.; Song, Y.; Kong, J.; Laoui, T.; Atieh, M.; Karnik, R. Selective Ionic Transport through Tunable Subnanometer Pores in Single-Layer Graphene Membranes. Nano Lett. 2014, 14, 1234-1241.

(81) Zhang, C.; Lively, R. P.; Zhang, K.; Johnson, J. R.; Karvan, O.; Koros, W. J. Unexpected Molecular Sieving Properties of Zeolitic Imidazolate Framework-8. J. Phys. Chem. Lett. 2012, 3, 2130-2134.

(82) Mi, B. Graphene Oxide Membranes for Ionic and Molecular Sieving. Science 2014, 343, 740-742.

(83) Deng, M.; Kwac, K.; Li, M.; Jung, Y.; Park, H. G. Stability, Molecular Sieving, and Ion Diffusion Selectivity of a Lamellar Membrane from Two-Dimensional Molybdenum Disulfide. Nano Lett. 2017, 17, 2342-2348.

(84) Labrador, N. Y.; Li, X.; Liu, Y.; Tan, H.; Wang, R.; Koberstein, J. T.; Moffat, T. P.; Esposito, D. V. Enhanced Performance of Si MIS Photocathodes Containing Oxide-Coated Nanoparticle Electrocatalysts. Nano Lett. 2016, 16, 6452-6459.

(85) Atkins, P.; De Paula, J. Physical Chemistry, 8th ed.; Oxford University Press: Oxford, 2006.

(86) Zhang, H.; Hou, J.; Hu, Y.; Wang, P.; Ou, R.; Jiang, L.; Liu, J. Z.; Freeman, B. D.; Hill, A. J.; Wang, H. Ultrafast Selective Transport of Alkali Metal Ions in Metal Organic Frameworks with Subnanometer Pores. Sci. Adv. 2018, 4, No. eaaq0066.

(87) Gao, L.; Chan, K. Y.; Li, C. V.; Xie, L.; Olorunyomi, J. F. Highly Selective Transport of Alkali Metal Ions by Nanochannels of Polyelectrolyte Threaded MIL-53 Metal Organic Framework. Nano Lett. 2019, 19, 4990-4996.

(88) Wang, G.; Zhang, B.; Wayment, J. R.; Harris, J. M.; White, H. S. Electrostatic-Gated Transport in Chemically Modified Glass Nanopore Electrodes. J. Am. Chem. Soc. 2006, 128, 7679-7686.

(89) Kim, Y.-J.; Choi, J.-H. Enhanced Desalination Efficiency in Capacitive Deionization with an Ion-Selective Membrane. Sep. Purif. Technol. 2010, 71, 70-75.

(90) Epsztein, R.; Shaulsky, E.; Dizge, N.; Warsinger, D. M.; Elimelech, M. Role of Ionic Charge Density in Donnan Exclusion of Monovalent Anions by Nanofiltration. Environ. Sci. Technol. 2018, 52, $4108-4116$.
(91) Ishii, Y.; Kobayashi, Y.; Watanabe, K.-i.; Koda, H.; Kunigami, H.; Kunigami, H. Fabrication of Silica/Platinum Core-Shell Particles by Electroless Metal Plating. Adv. Powder Technol. 2019, 30, 829-834.

(92) Cloarec, J. P.; Chevalier, C.; Genest, J.; Beauvais, J.; Chamas, H.; Chevolot, Y.; Baron, T.; Souifi, A. $\mathrm{pH}$ Driven Addressing of Silicon Nanowires onto Si3N4/SiO2 Micro-Patterned Surfaces. Nanotechnology 2016, 27, No. 295602.

(93) Richards, L. A.; Schafer, A. I.; Richards, B. S.; Corry, B. The Importance of Dehydration in Determining Ion Transport in Narrow Pores. Small 2012, 8, 1701-1709.

(94) Sahu, S.; Di Ventra, M.; Zwolak, M. Dehydration as a Universal Mechanism for Ion Selectivity in Graphene and Other Atomically Thin Pores. Nano Lett. 2017, 17, 4719-4724.

(95) Epsztein, R.; DuChanois, R. M.; Ritt, C. L.; Noy, A.; Elimelech, M. Towards Single-Species Selectivity of Membranes with Subnanometre Pores. Nat. Nanotechnol. 2020, 15, 426-436.

(96) Gouaux, E.; MacKinnon, R. Principles of Selective Ion Transport in Channels and Pumps. Science 2005, 310, 1461-1465.

(97) Sun, P.; Zheng, F.; Zhu, M.; Song, Z.; Wang, K.; Zhong, M.; Wu, D.; Little, R. B.; Xu, Z.; Zhu, H. Selective Trans-Membrane Transport of Alkali and Alkaline Earth Cations through Graphene Oxide Membranes Based on Cation- $\pi$ Interactions. ACS Nano 2014, 8, 850-859.

(98) Epsztein, R.; Shaulsky, E.; Qin, M.; Elimelech, M. Activation Behavior for Ion Permeation in Ion-Exchange Membranes: Role of Ion Dehydration in Selective Transport. J. Membr. Sci. 2019, 580, 316-326.

(99) Richards, L. A.; Schafer, A. I.; Richards, B. S.; Corry, B. Quantifying Barriers to Monovalent Anion Transport in Narrow NonPolar Pores. Phys. Chem. Chem. Phys. 2012, 14, 11633-11638.

(100) Sigurdardottir, S. B.; DuChanois, R. M.; Epsztein, R.; Pinelo, M.; Elimelech, M. Energy Barriers to Anion Transport in Polyelectrolyte Multilayer Nanofiltration Membranes: Role of IntraPore Diffusion. J. Membr. Sci. 2020, 603, No. 117921.

(101) Tansel, B. Significance of Thermodynamic and Physical Characteristics on Permeation of Ions During Membrane Separation: Hydrated Radius, Hydration Free Energy and Viscous Effects. Sep. Purif. Technol. 2012, 86, 119-126.

(102) Zwolak, M.; Wilson, J.; Di Ventra, M. Dehydration and Ionic Conductance Quantization in Nanopores. J. Phys.: Condens. Matter 2010, 22, No. 454126.

(103) Jain, T.; Rasera, B. C.; Guerrero, R. J.; Boutilier, M. S.; O’Hern, S. C.; Idrobo, J. C.; Karnik, R. Heterogeneous SubContinuum Ionic Transport in Statistically Isolated Graphene Nanopores. Nat. Nanotechnol. 2015, 10, 1053-1057.

(104) Wang, M.; Shen, W.; Ding, S.; Wang, X.; Wang, Z.; Wang, Y.; Liu, F. A Coupled Effect of Dehydration and Electrostatic Interactions on Selective Ion Transport through Charged Nanochannels. Nanoscale 2018, 10, 18821-18828.

(105) Marcus, Y. Ionic Radii in Aqueous Solutions. Chem. Rev. 1988, 88, 1475-1498.

(106) Marcus, Y. The Thermodynamics of Solvation of Ions Part 2.-The Enthalpy of Hydration at 298.15 K. J. Chem. Soc., Faraday Trans. 1 1987, 83, 339-349.

(107) Song, C.; Corry, B. Intrinsic Ion Selectivity of Narrow Hydrophobic Pores. J. Phys. Chem. B 2009, 113, 7642-7649.

(108) Liu, Y.-Y.; Hua, X.; Zhang, Z.; Zhang, J.; Zhang, S.; Hu, P.; Long, Y.-T. pH-Dependent Water Clusters in Photoacid Solution: Real-Time Observation by ToF-SIMS at a Submicropore Confined Liquid-Vacuum Interface. Front. Chem. 2020, 8, No. 731.

(109) Liu, X.; Lu, W.-C.; Wang, C. Z.; Ho, K. M. Energetic and Fragmentation Stability of Water Clusters $(\mathrm{H} 2 \mathrm{O}) \mathrm{n}, \mathrm{n}=2-30$. Chem. Phys. Lett. 2011, 508, 270-275.

(110) Li, X.; Zhang, H.; Wang, P.; Hou, J.; Lu, J.; Easton, C. D.; Zhang, X.; Hill, M. R.; Thornton, A. W.; Liu, J. Z.; Freeman, B. D.; Hill, A. J.; Jiang, L.; Wang, H. Fast and Selective Fluoride Ion Conduction in Sub-1-Nanometer Metal-Organic Framework Channels. Nat. Commun. 2019, 10, No. 2490. 
(111) Dalmark, M.; Wieth, J. O. Temperature Dependence of Chloride, Bromide, Iodide, Thiocyanate and Salicylate Transport in Human Red Cells. J. Physiol. 1972, 224, 583-610. 